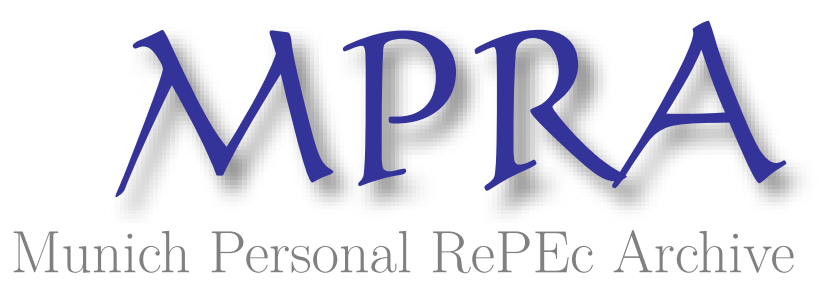

Estimating Intertemporal and Intratemporal Substitutions When Both Income and Substitution Effects Are Present: The Role of Durable Goods

pakos, michal

CERGE-EI

1 July 2011

Online at https://mpra.ub.uni-muenchen.de/32453/

MPRA Paper No. 32453, posted 27 Jul 2011 17:51 UTC 


\title{
Estimating Intertemporal and Intratemporal Substitutions When Both Income and Substitution Effects Are Present: The Role of Durable Goods
}

\author{
Michal PAKoš \\ Center for Economic \& Graduate Education, Department of Economics, Charles University Economics Institute, \\ Academy of Sciences of the Czech Republic, Politickych Veznu 7, 11121 Prague 1, Czech Republic \\ (michal.pakos@cerge-ei.cz)
}

\begin{abstract}
Homotheticity induces a dramatic statistical bias in the estimates of the intratemporal and intertemporal substitutions. I find potent support in favor of nonhomotheticity in aggregate consumption data, with nondurable goods being necessities and durable goods luxuries. I obtain the intertemporal substitutability negligible (0.04), a magnitude close to Hall's (1988) original estimate, and the intratemporal substitutability between nondurable goods and service flow from the stock of durable goods small as well (0.18). Despite that, due to the secular decline of the rental cost, the budget share of durable goods appears trendless.
\end{abstract}

KEY WORDS: Durable goods; Intertemporal substitution; Intratemporal substitution; Nonhomotheticity.

\section{INTRODUCTION}

The elasticities of intertemporal (across time) and intratemporal (within period and across goods) substitutions are the two central parameter inputs into all modern macroeconomic models. They dramatically influence the quantitative implications of various economic policy decisions (Hall 1988). First, the degree of the intertemporal substitutability is by far the most important determinant of the response of saving and consumption to predictable changes in the real interest rate. If expectations of real interest rates shift, there ought to be a corresponding shift in the rate of change of consumption expenditures, and hence the amount of consumption itself. The magnitude of this intertemporal substitutability, denoted EIS, is measured by the percentage response of the total consumption expenditures to a percentage change in the real interest rate expectations, ceteris paribus.

Furthermore, in a two-good economy with consumer durable goods, and, more generally, in multigood economies, the magnitude of the intratemporal substitution indirectly affects the measure of the intertemporal substitution. A commonly advanced but fallacious argument is that the real interest rate positively affects the user cost of consumer durables, and therefore a surge in interest rates leads to an increase in the user cost, with consumers rationally substituting from the service flow yielded by the durable goods to nondurable consumption. However, intertemporal substitutability is a ceteris paribus measure, and it is straightforward to show that as long as the consumption index over the nondurable goods and the service flow from durable goods is homogeneous of degree one, intratemporal substitutability does not affect intertemporal substitutability. The situation, however, is diametrically opposite in the case of nonhomotheticity (nonhomogeneous consumption index) wherein the Engel's income expansion paths are nonlinear functions.

Second, the magnitude of the elasticity of intratemporal substitution may be important for asset pricing. It, in addition to the coefficient of risk aversion, determines the variability of the marginal utility and hence asset risk premia. In fact, low substitutability between consumption goods means that a small variation in nondurable consumption translates into dramatic fluctuations in marginal utility. This raises the intriguing question whether the consumption risk of the stock market is really as small as the single-good economies seem to imply.

A large literature focuses on the estimation of these two parameters. In his provocative paper, Hall presents estimates of the elasticity of the intertemporal substitution "... that are small. Most of them are also quite precise, supporting the strong conclusion that the elasticity is unlikely to be much above 0.1 , and may well be zero." Using improved inference methods, Hansen and Singleton (1983) find that there is less precision and even obtain estimates that are negative. Using international data, Campbell (1999) estimates the elasticity of intertemporal substitution statistically and economically insignificant. However, these studies assume that the felicity function is separable over nondurables and durables (see Lewbel 1987 for another criticism of Hall's model). In response, Mankiw $(1982,1985)$ and Ogaki and Reinhart (1998) enrich the model by explicitly introducing the service flow from consumer durables but unfortunately assume linear Engel curves. Mankiw finds that the service flow from consumer durables is itself more responsive to the interest rates, and estimates a large elasticity of substitution for durable goods. Focusing on nonseparability across goods, Ogaki and Reinhart find that there is quite a large intertemporal substitutability when both nondurable and durable goods are considered.

One important criticism of the Ogaki and Reinhart's empirical results is that they work with homothetic preferences and

() 2009 American Statistical Association Journal of Business \& Economic Statistics Accepted for publication DOI: 10.1198/jbes.2009.07046 


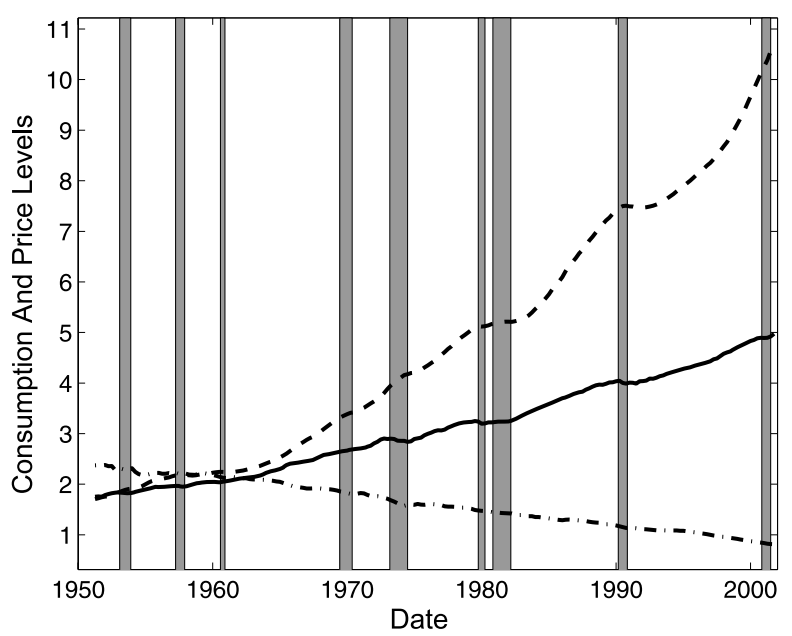

Figure 1. Historical consumption series and their relative price. Notes: The plot portrays the time-series of the real nondurable consumption (solid line), the stock of durable goods (dashed line), and their relative price (dash-dot line). Bars represent NBER recessions. Sample size 1951:I-2001:IV.

thus their relative demand function for durable goods is free from potentially significant income effects. The correct modeling of nonhomotheticity in such relative demand turns out to be essential in order to obtain unbiased estimates of the magnitudes of the intratemporal and intertemporal substitutions. Empirically, the ratio of durables over nondurables has been trending up secularly (see Figure 1). The mainstream interpretation is that investors optimally substituted (in the sense of Hicks) consumer durables for nondurable goods in response to their falling price, with income effects playing no role whatsoever (Eichenbaum and Hansen 1990; Ogaki and Reinhart 1998). However, durable goods may not have an easy substitute, and therefore we would expect a priori the Hicksian price effects to be relatively small. I illustrate this point with an example. Suppose the consumer faces the choice of commuting to work by either taxi or by renting a car. If the car rental cost increases relative to the cost of taxi, the consumer gets a compensation in order to hold his real income constant, and he alters his consumption of car services little relative to the taxi, the Hicksian price effect is small. Note that it is important to compensate the consumer so that we isolate the pure price effect. It is common to use the word "substitute" in the sense of "serving in place of another" (Oxford Dictionary). However, that is not the technical meaning of the word. It confuses income versus substitution effects precisely because in both cases consumers use another consumption good in place of the original one. But these two effects are distinct reaction channels to a price change. The presented empirical results appear to indicate that the Hicksian substitution effects are smaller than we thought, and thus the income effects should be very important to fit the relative demand function for durable goods.

In order to see the effects of this misspecification, I use the two-step cointegration-Euler equation approach pioneered by Cooley and Ogaki (1996) and Ogaki and Reinhart (1998), and allow for (i) nonseparability across goods (nondurables and the service flow from consumer durables) and (ii) a fairly general form (in fact, my proposed preference specification allows for time-varying expenditureelasticities of nondurable goods and the service flow from consumer durables as long as their ratio is a constant) of nonhomotheticity in the relative demand function for durables by generalizing the constant-elasticity-ofsubstitution (CES) felicity function. In the first step, using cointegration techniques, I obtain super-consistent estimates of the elasticity of intratemporal substitution and the ratio of withinperiod expenditure elasticities. In the second step, I invoke the Hansen's (1982) Generalized Method of Moments to efficiently estimate the rest of the preference parameter vector, and formally test the model. Then, following Atkeson and Ogaki (1996), I define the elasticity of intertemporal substitution EIS as the inverse of the elasticity of the marginal utility of the total consumption expenditures. This step requires a numerical solution of the second stage of two-stage budgeting to construct the indirect felicity function and its partial derivatives.

The results of the paper are intriguing. First, consistent with microeconomic studies, I find that the Engel curves are not linear, and hence the preferences exhibit nonhomotheticity, with durable goods being luxury goods and nondurable goods necessary goods. Second, the budget share of durable goods is time varying, living between $7.3 \%$ and $20.4 \%$. It appears trendless, despite the corresponding income elasticity being greater than one, precisely as the rental cost of durables trends down secularly. Hall estimates the EIS for nondurables close to zero whereas Mankiw estimates the EIS for consumer durable goods economically significant. Because the consumption basket is a weighted average of nondurable goods (negligible EIS) and durable goods (significant EIS), and the budget share of durable goods is comparatively small, I confirm the intuitive result that the elasticity of intertemporal substitution EIS for the total consumption expenditures is economically small as well.

It is well known that adjustment costs play an essential role in the consumption of durable goods (Bernanke 1984; Lam 1989; Grossman and Laroque 1990; Eberly 1994). Mankiw (1985) concludes that "... future work should pay closer attention to the role of adjustment costs. The model that took account of the adjustment process would be better suited for examining the effects of shorter term fluctuations in the real interest rate." Ogaki and Reinhart (1998) correctly point out that one of the big advantages of the two-stage cointegration-Euler equations approach is that "... it is robust to various specifications of adjustment costs, relying on the cointegration properties between the observed and the desired stock of durables in the presence of adjustment costs, which is discussed in Caballero (1993)." The inference based on the cointegrating regressions yields consistent estimates as long as adjustment costs do not affect the long-run behavior of the service flow from consumer durables. Furthermore, it can be shown that the Euler equation for nondurable consumption is robust to various forms of adjustment costs for durable goods consumption. Unfortunately, many related studies, such as Eichenbaum and Hansen (1990), among others, do not allow implicitly nor explicitly in their estimation for adjustment costs.

\section{THEORETICAL FRAMEWORK}

\subsection{Model}

Consider an endowment economy populated with homogeneous households of measure one. Suppose further that their 
preferences are representable by the Von Neuman-Morgenstern time-separable expected utility functional, defined over the stream of consumption $\left\{C_{t}\right\}_{t \geq 0}$. Formally

$$
U\left(\left\{C_{t}\right\}_{t \geq 0}\right) \triangleq E\left\{\sum_{t=0}^{\infty} \beta^{t} u\left(C_{t}\right)\right\} .
$$

I denote by $\beta \in(0,1)$ the subjective rate of time preference. The felicity function $u: \mathbb{R}^{+} \rightarrow \mathbb{R}^{+}$is of the following isoelastic form

$$
u\left(C_{t}\right)=\frac{1}{1-1 / \sigma} C_{t}^{1-1 / \sigma},
$$

where the parameter $\sigma>0$ is a (biased under nonhomotheticity) measure of the elasticity of intertemporal substitution (EIS). Next, I specify the consumption index $C: \mathbb{R}^{+} \times \mathbb{R}^{+} \rightarrow$ $\mathbb{R}^{+}$over the nondurable goods $c_{t}$ and the service flow $s_{t}$ from consumer durables as

$$
C\left(c_{t}, s_{t}\right) \triangleq\left\{(1-\tilde{a}) \times c_{t}^{1-1 / \theta}+\tilde{a} \times s_{t}^{1-\eta / \theta}\right\}^{\theta /(\theta-1)},
$$

where $\tilde{a} \in(0,1)$ is the preference weight. Observe that the consumption index $C\left(c_{t}, s_{t}\right)$ allows for potential nonhomotheticity. Dunn and Singleton (1986) impose that the consumption index $C\left(c_{t}, s_{t}\right)$ is homothetic and Cobb-Douglas; their implied parameters $\theta=1$ and $\eta=1$. Eichenbaum and Hansen (1990) and Ogaki and Reinhart (1998) relax the restrictive elasticity constraint that the intratemporal substitution $\theta=1$, but still keep the homotheticity postulate $\eta=1$. As it will become clear later on, nonhomotheticity, by lifting the assumption of no income effects, turns out to be economically, but also statistically, significant feature of the data. It markedly improves the fit of the relative demand for consumer durables.

Using the second stage of two-stage budgeting, I interpret the parameter $\eta \in \mathbb{R}$ as the ratio of within-period expenditure elasticities of nondurables and services flow. Empirically, I find $\eta<1$, and hence durable goods are luxuries and nondurable goods necessities. Homothetic preferences correspond to the restriction $\eta=1$. On the technical side, it is also to be noted that this preference specification easily accommodates variable within-period expenditure elasticities of both goods as long as their ratio remains constant.

Many studies implicitly use durable goods by assuming that nondurable consumption and the service flow from durables enter the felicity function separably (Hansen and Singleton 1982, 1983). Eichenbaum and Hansen (1990) find empirical evidence in favor of nonseparability. Fleissig, Gallant, and Seater (2000) derive a seminonparametric utility function with both nondurable goods and consumer durable goods, and find that CRRA preferences defined only over nondurable goods are severely misspecified. They also discover evidence in favor of significant nonseparabilities across the consumption goods.

I interpret the parameter $\theta>0$ as a measure of the intratemporal substitution, which itself is precisely gauged by the elasticity of intratemporal substitution, denoted ES. The two, however, are related by the condition derived in Appendix D, ES= $\theta+\varepsilon_{d d}^{*} \times(\eta-1)$, where $\varepsilon_{d d}^{*}$ is the Hicksian own-price elasticity of the demand for the service flow from durable goods. I shall discuss this point deeper hereafter.
The law of motion of the consumer durables $d_{t}$ is given by the linear difference equation

$$
d_{t}=(1-\delta) d_{t-1}+i_{t}
$$

where $i_{t}$ denotes durable goods investment, and $\delta \in(0,1)$ is the corresponding depreciation rate. The flow of services $s_{t}$ itself is produced by a linear household production function (Stigler and Becker 1977; Mankiw 1985), which is time-independent and state-independent, $s_{t} \triangleq A \times d_{t}, A>0$. The budget constraint is standard and it is not displayed here.

Note that the preference weight $\tilde{a}$ and the household productivity $A$ cannot be separately identified. As a result, I take a monotonic transformation of the utility function, reparametrizing the consumption index as

$$
C \triangleq C\left(c_{t}, d_{t}\right)=\left\{c_{t}^{1-1 / \theta}+a d_{t}^{1-\eta / \theta}\right\}^{\theta /(\theta-1)},
$$

where I denote $a \triangleq \tilde{a} A^{1-\eta / \theta} /(1-\tilde{a})>0$.

\subsection{First-Order Conditions}

The intertemporal marginal rate of substitution $m_{t+1}$ is given by the ratio the marginal utilities of nondurable goods,

$$
\begin{aligned}
m_{t+1} & \triangleq \frac{\beta U_{c}\left(c_{t+1}, d_{t+1}\right)}{U_{c}\left(c_{t}, d_{t}\right)} \\
& =\beta\left(\frac{c_{t+1}}{c_{t}}\right)^{-1 / \sigma} \times\left(\frac{f_{t+1}}{f_{t}}\right)^{-(\theta-\sigma) /(\sigma(\theta-1))},
\end{aligned}
$$

where $f_{t}$ is defined as $f_{t} \triangleq 1+a d_{t}^{1-\eta / \theta} / c_{t}^{1-1 / \theta}$.

My model with nonhomothetic preferences does imply that the intertemporal marginal rate of substitution is stationary despite Assumption 1.

Assumption 1. The vector time series

$$
\left[\log c_{t}, \log d_{t}, \log q_{t}\right]^{\prime}
$$

are integrated of order one, that is, $I(1)$.

Proposition 2. The marginal rate of substitution $m_{t+1}$ is stationary.

\section{Proof. See Appendix B.}

Intuitively, $m_{t+1}$ is the growth rate of the marginal utility $\beta^{t} U_{c}\left(c_{t}, d_{t}\right)$, and if indeed it were integrated of order 1 , the marginal utility would have to be integrated of order 2 . Hence, the nonlinear function, the marginal utility, would turn an $I(1)$ variable into I(2) one, which is impossible.

Standard variational argument implies that the intertemporal first-order condition is the following ubiquitous Euler equation

$$
1=\mathbb{E}_{t}\left[m_{t+1} R_{i t+1}\right]
$$

where $R_{i t+1}$ is the (gross) return on test asset $i$.

The intratemporal first-order condition states that the marginal utility per last dollar spent must be the same across all consumption categories. Formally,

$$
\frac{U_{c}\left(c_{t}, d_{t}\right)}{1}=\frac{U_{d}\left(c_{t}, d_{t}\right)}{r c_{t}},
$$


where $r c_{t}$ stands for the rental cost of consumer durables. Note that nondurable goods are the numeraire. Rearranging, we obtain the familiar condition that the marginal rate of substitution equals the relative price.

$$
\frac{U_{d}\left(c_{t}, d_{t}\right)}{U_{c}\left(c_{t}, d_{t}\right)}=r c_{t} .
$$

No arbitrage, consequently, links the rental cost of durable goods $r c_{t}$ and their relative "cum-dividend" price $q_{t}$ by means of the following present-value formula:

$$
r c_{t}=q_{t}-(1-\delta) \mathbb{E}_{t}\left\{m_{t+1} q_{t+1}\right\} .
$$

Intuitively, suppose we purchase one unit of durable goods at price $q_{t}$, which after one period depreciates to $1-\delta$. We can sell it for $(1-\delta) q_{t+1}$. The implicit rental cost $r c_{t}$ is the net present value (NPV) of this transaction, that is,

$$
r c_{t}=q_{t}-(1-\delta) \mathbb{E}_{t}\left\{m_{t+1} q_{t+1}\right\},
$$

where the stochastic discount factor just equals the intertemporal marginal rate of substitution.

My model implies, under mild conditions, a certain longrun relationship between nondurable consumption, the stock of consumer durable goods, and their relative price. To prove that, I appeal to the well-established fact in empirical macroeconomics that the asset prices to current income flows, such as price-dividend ratios of common stocks, are stationary, that is, $I(0)$. Durable goods may be thought of as assets that pay a regular stream of rental costs, and hence one naturally conjectures that the corresponding price-rental cost ratio ought to be $I(0)$. That the presented model inherently implies such a longrun relationship is proved in the following proposition.

Proposition 3. The log of the rental cost of durable goods $\log r c_{t}$ and the $\log$ of the durable goods price $\log q_{t}$ share a common stochastic trend, with the cointegrating vector $[1,-1]^{\prime}$.

\section{Proof. See Appendix C.}

The next proposition turns out to be key in the empirical section. It allows me to estimate a subset of preference parameters, namely $\theta$ and $\eta$, superconsistently by applying the Johansen (1991) methodology, and thus immensely simplifies the econometric analysis of the model-implied conditional Euler equations by reducing the cardinality of the parameter space.

Proposition 4. The log of nondurable consumption, the log of the stock of durable goods and their relative price share a single common stochastic trend, with the corresponding cointegrating vector

$$
[1,-\eta,-\theta]^{\prime} .
$$

Proof. Direct calculation of the intratemporal marginal rate of substitution yields that

$$
r c_{t}=a \times d_{t}^{-\eta / \theta} / c_{t}^{-1 / \theta} .
$$

Taking natural logarithm of both sides,

$$
\log \left(r c_{t}\right) \propto(1 / \theta) \log c_{t}-(\eta / \theta) \log d_{t} .
$$

Proposition 3 tells us that

$$
\log r c_{t}-\log q_{t} \sim I(0) \text {. }
$$

Upon substitution, and rearranging, I obtain the claimed longrun relationship

$$
\log c_{t}-\theta \log q_{t}-\eta \log d_{t} \sim I(0) .
$$

Evidently, the cointegrating vector is $[1,-\eta,-\theta]^{\prime}$. The uniqueness is implied by the fact that $\theta$ and $\eta$ are structural preference parameters.

\subsection{Interpretation of the Parameters $\theta$ and $\eta$}

The preference parameters $\theta$ and $\eta$ are easily interpreted in the case of deterministic setup using the second stage of twostage budgeting, which holds due to the weak separability of the consumer preferences (Deaton and Muellbauer 1980). I here summarize the results and refer the interested reader to Appendix D for formal derivations.

Each period the consumer optimally chooses his consumption expenditure $e_{t}$. Then, depending on the rental cost of consumer durables, she chooses her allocation of nondurable consumption and the service flow from renting consumer durables. The elasticity of intratemporal substitution ES—substitution across goods within a given time-period holding the real income constant, gauges how much the relative Hicksian demand for durable goods changes in response to a percent change in the rental cost of consumer durables $r c$. In the model, its yardstick, but not a precise measure, is the parameter $\theta$. The two are related by the equation $E S=\theta+\varepsilon_{d d}^{*} \times(\eta-1)$, where $\varepsilon_{d d}^{*}$ is the Hicksian own-price elasticity of the demand for the service flow of durable goods. Furthermore, the expenditure elasticity measures how much the demand for a consumption good changes in a response to a $1 \%$ rise in expenditures, ceteris paribus. For future reference, I denote the expenditure elasticity of nondurable consumption $\eta_{c}$ and that of the service flow $\eta_{d}$. It turns out that the parameter $\eta$ is a ratio of these two elasticities, namely, $\eta=\eta_{c} / \eta_{d}$. That these claims hold true may be easily verified by comparing the slopes in the cointegrating regressions based on (i) the intratemporal first-order condition and (ii) the first-order condition from the second stage of two-stage budgeting (D.18), derived in Appendix D.

When both income and substitution effects are present, the relative demand function takes the form

$$
d \log \left(c_{t} / d_{t}\right)=\underbrace{E S \times d \log r c_{t}}_{\text {substitution effect }}+\underbrace{\left(\eta_{c}-\eta_{d}\right) \times d \log \hat{e}_{t}}_{\text {income effect }} .
$$

The parameter $\hat{e}_{t}$ denotes the real expenditure on both consumption goods, measured in terms of the composite good (see also Appendix D). This equation shows that the relative demand changes are either due to substitution effect or due to income effect. It offers a framework to understand the secular rise in the consumption of durable goods relative to nondurable goods. The typical interpretation is that consumers substituted (in the sense of Hicks) to durable goods in response to their falling relative price, with income effects playing no role at all. This corresponds to the case where elasticity of substitution ES is large [Eichenbaum and Hansen's (1990) estimate is $E S=0.91$. Ogaki and Reinhart's (1998) estimate is greater than one, $E S>1]$ and the preferences are homothetic, which automatically eliminates the income effect. Formally,

$$
d \log \left(c_{t} / d_{t}\right)=E S \times d \log r c_{t} .
$$


As the empirical results in later sections indicate, after correcting for the income effects, the substitutability ES between the services flow and nondurables is smaller than estimated by Eichenbaum and Hansen (1990) and Ogaki and Reinhart (1998), and hence significant nonhomotheticity is dictated. Formally, $\left(\eta_{c}-\eta_{d}\right) \times d \log \hat{e}_{t}$ is not negligible, and thus affects the estimates of both the intratemporal and intertemporal substitutions.

The real income in the United States economy has been rising steadily and thus the previous equation suggests that $\eta_{c}-\eta_{d}<0$. Because the average income elasticity must be one, we get the plausible result that durable goods are luxury goods and nondurable goods are necessary goods, that is, $\eta_{c}<1<\eta_{d}$. Empirically, I estimate $\eta_{d} \in[1.460,1.579]$ and $\eta_{c} \in[0.882,0.954]$. For comparison, Costa (2001) estimates the income elasticities for food at home 0.47 in 1960-1994 and 0.62 in 1917-1935. Those for total food are 0.65 in 1960-1994 and 0.68 in 1917-1935 and in 1888-1917.

\section{EMPIRICAL SECTION}

\subsection{Consumption and Asset Return Data}

Quarterly consumption data are from the U.S. national accounts as available from the Federal Reserve Bank of St. Louis. I measure nondurable consumption $c_{t}$ as the sum of real personal consumption expenditures (PCE) on nondurable goods and services. Consumer durables include furniture, motor vehicles, and jewelry and watches. The data were kindly provided to me by Motohiro Yogo of Wharton. Note that these time series, after aggregated to annual quantities, are exactly consistent with the year-end estimates of the chained quantity index for net stock of consumer durables as published by the Bureau of Economic Analysis (BEA). The implied depreciation rate for the durable goods as a whole is approximately $6 \%$ per quarter. Both nondurable goods and services, and durable goods are converted to per-capita values by dividing by the population size. The relative price of consumer durables $q$ is calculated as the ratio of the price index for PCE on durable goods to the price index for PCE on nondurable goods and services. The data are available for the period 1951:I-2001:IV.

The asset return data consist of the time series of the monthly return on the U.S. Treasury Bills, and the value-weighted return on all NYSE, AMEX, and NASDAQ stocks (from CRSP), both converted to quarterly values. The real returns are computed by deflating the nominal returns with the consumer price index (CPI), obtained from the Federal Reserve Bank of St. Louis.

\subsection{Intratemporal First-Order Condition}

Intratemporal First-Order Condition as a Cointegrating Regression. As shown in the theoretical section, Proposition 4, the intratemporal first-order condition is inherently log-linear,

$$
\log c_{t} \propto \theta \log q_{t}+\eta \log d_{t}+\varepsilon_{t}
$$

and the disturbace term $\varepsilon_{t}$ is statistically stationary, that is, $\varepsilon_{t} \sim I(0)$. Therefore, the model implies a certain single longrun relationship between nondurable goods, consumer durables, and their relative price. Hence, I am able to estimate the parameters $\theta$ and $\eta$ superconsistently by extracting the information from the trends. This idea is borrowed from the related paper by Ogaki and Reinhart (1998), who also estimate the elasticity of intratemporal substitution in the presence of durable goods. They focus on the homothetic case $\eta=1$, in which the true elasticity of intratemporal substitution $E S=\theta$. Their regression specification is as follows:

$$
\log \left(c_{t} / d_{t}\right) \propto \theta \log q_{t}+\varepsilon_{t} .
$$

The presence of significant nonhomotheticity biases upward the estimate of the intratemporal substitutability. The relative demand for consumer durable goods may change either due to income effect or due to substitution effect. Homotheticity dictates that it was Hicksian substitution in response to a secular change in the relative price that led consumers to purchase more durable goods. Neglecting income effects forces the substitution effects to be larger to fit the secular trend in the consumption of durable goods relative to nondurable goods. In general, considering income effects may be important, in particular for goods with large expenditure shares and/or no easy substitutes such as housing or consumer durables, as Slutsky equation says that the income effects are proportional to the expenditure shares. Empirically, Eichenbaum and Hansen (1990) use CES aggregator over nondurables and durables but impose homotheticity. They estimate both intratemporal and intertemporal equations jointly using GMM and get the elasticity of intratemporal substitution $E S=0.91$. Using the same preference specification but estimating the elasticity of substitution using cointegration techniques, Ogaki and Reinhart (1998) cannot reject the null hypothesis $H_{0}: \theta \geq 1$. As argued before, neglecting income effects biases upward the estimate of the elasticity of substitution ES, and thus the parameter $\theta$. This observation is confirmed empirically hereafter.

Unit Roots. I test the null hypothesis that the natural logarithm of the series, $\log c_{t}, \log d_{t}$, and $\log q_{t}$, are difference stationary against the alternative hypothesis of trend stationarity, invoking the efficient unit root tests of Elliott, Rothenberg, and Stock (1996) and Ng and Perron (2001). In all cases, I am unable to reject the hypothesis that the data are difference stationary at conventional significance levels (see Table 1).

Johansen's (1991) Cointegration Methodology. Both BIC and HQ criteria suggest that the $3 \times 1$ vector

$$
\left(\log c_{t}, \log d_{t}, \log q_{t}\right)^{\prime}
$$

follows a vector autoregression of order 2, $\operatorname{VAR}(2)$, in levels. The lag length $p$ for the vector error correction model (VECM) is then $p=2-1=1$. Since the vector time series are trending,

Table 1. Tests for the null of difference stationarity

\begin{tabular}{lccc}
\hline \hline & \multicolumn{3}{c}{ Test statistics } \\
\cline { 2 - 4 } Time series & ERS test & DFGLS test & MPP test \\
\hline $\log d_{t}$ & 6.380 & -2.487 & -2.663 \\
$\log c_{t}$ & 8.340 & -2.246 & -2.330 \\
$\log q_{t}$ & 48.219 & -0.006 & -0.076 \\
\hline
\end{tabular}

NOTE: The null hypothesis is that the respective series contain a unit root. The alternative hypothesis is that there is a linear time trend. Tests are as follows: ERS is the ElliottRothenberg-Stock test, DFGLS is the DF test with GLS detrending, and MPP is the modified Phillips-Perron test. None of the presented statistics are significant at conventional significance levels. 
Table 2. Analysis of cointegration

Panel A. Johansen's likelihood ratio tests

\begin{tabular}{lcccc}
\hline \hline \multirow{2}{*}{$\begin{array}{l}\text { No. coint. vectors } \\
r\end{array}$} & \multicolumn{3}{c}{ Test statistics } \\
\cline { 2 - 5 } & $L R_{\text {trace }}(r)$ & $95 \% \mathrm{CV}, L R_{\text {trace }}(r)$ & $L R_{\max }(r)$ & $95 \% \mathrm{CV}, L R_{\max }(r)$ \\
\hline 0 & $30.899^{*}$ & 29.680 & $24.587^{*}$ & 20.970 \\
1 & 6.313 & 15.410 & 6.308 & 14.070 \\
2 & 0.005 & 3.760 & 0.005 & 3.760 \\
\hline
\end{tabular}

Panel B. Estimated vector error-correction model

\begin{tabular}{lcccccc}
\hline \hline & Intercept & $\log c_{t-1}-\hat{\eta} \log d_{t-1}-\hat{\theta} \log q_{t-1}$ & $\Delta \log c_{t-1}$ & $\Delta \log d_{t-1}$ & $\Delta \log q_{t-1}$ & $R^{2}$ (in \%) \\
\hline$\Delta \log c_{t}$ & -0.002 & 0.035 & 0.261 & -0.063 & 0.051 & 11.490 \\
& $(0.003)$ & $(0.020)$ & $(0.075)$ & $(0.078)$ & $(0.054)$ & \\
$\Delta \log d_{t}$ & -0.006 & 0.039 & 0.090 & 0.774 & 0.002 & 80.730 \\
& $(0.002)$ & $(0.009)$ & $(0.035)$ & $(0.036)$ & $(0.025)$ & 13.530 \\
$\Delta \log q_{t}$ & 0.008 & -0.065 & 0.041 & 0.008 & 0.256 & $(0.070)$ \\
& $(0.004)$ & $(0.026)$ & $(0.097)$ & $(0.101)$ & $(0.07)$ & \\
\hline
\end{tabular}

Panel C. Estimated cointegrating vector

\begin{tabular}{|c|c|c|c|c|}
\hline \multirow[b]{2}{*}{ Preference parameter } & \multicolumn{2}{|c|}{ Johansen's analysis } & \multicolumn{2}{|c|}{ Swensen's bootstrap estimates } \\
\hline & Est. & Asym. s.e. & Est. & Asym. s.e. \\
\hline$\theta$ & 0.083 & $(0.075)$ & 0.082 & $(0.080)$ \\
\hline$\eta$ & 0.604 & $(0.041)$ & 0.605 & $(0.013)$ \\
\hline
\end{tabular}

NOTE: $\quad \mathrm{CV}$ stands for critical value. Both Bayesian Information (BIC) and Hannan-Quinn (HQ) criteria suggest that the vector $\left(\log c_{t}, \log d_{t}, \log q_{t}\right)^{\prime}$ follows a VAR(2). The $\log$ likelihood function attains a maximum of 2458.18, with 202 degrees of freedom. Sample period 1951:I-2001:IV. Standard errors are in parentheses.

the Johansen Likelihood Ratio (LR) tests are computed assuming unrestricted constant. Denote $H_{0}(r): r=r_{0}$ the null hypothesis of exactly $r_{0}$ cointegrating vectors, and $H_{1}(r): r>r_{0}$ the alternative hypothesis of more than $r_{0}$ such vectors. Based on Table 2, panel A, I cannot accept the null hypothesis $H_{0}(0)$ at the $5 \%$ significance level, but I accept $H_{0}(1)$. Therefore, according the Johansen's trace statistic, there is exactly one cointegrating vector. Johansen's maximum eigenvalue statistic $L R_{\max }$ leads to exactly the same conclusion, providing an additional support for the single long-run relationship between the logs of nondurable goods, consumer durable goods and their relative price.

Swensen's (2006) Bootstrap Algorithm for Determining the Cointegration Rank. It is well known that the asymptotic approximations to the Johansen's trace and maximum eigenvalue tests are not always accurate. Swensen suggests a bootstrap algorithm as an alternative, and I implement it as an important robustness check. Due to their high costs, I perform 2000 experiments, and subsequently compute the percentile confidence intervals and $p$-values for the trace statistic. I easily reject the hypothesis of no-cointegration, with the corresponding $p$-value being $5 \mathrm{e}-4$. Hence, there is at least one cointegrating vector. I test the null hypothesis $H_{0}(1): r=1$ versus the alternative of at least two cointegrating vectors. The resultant $p$-value equals 0.381 , and I am unable to reject the null, providing further empirical support in favor of a single stochastic trend in the logs of nondurable consumption, the stock of consumer durable goods and their relative price (see also Figure 2). Note that this result is essential as the model in fact predicts that these variables are cointegrated, and therefore a failure to find evidence in favor thereof would lead to outright rejection of the model.
Estimated Cointegrating Vector: Johansen Methodology. I estimate the corresponding vector error correction model by the method of maximum likelihood. The estimates are reported in Table 2, panel C. The nonhomotheticity measure $\eta$ comes economically and statistically less than one, providing evidence against the null hypothesis of homotheticity. The substitutability yardstick $\theta$ is estimated economically small, around 0.08 , and statistically less than the estimates of Ogaki and Reinhart (1998). I am able to easily reject the hypothesis that the consumption index $C\left(c_{t}, s_{t}\right)$ is of the homogeneous Cobb-Douglas functional form.

Estimated Cointegrating Vector: Swensen Methodology. As a byproduct of bootstrapping the cointegration rank, I obtain estimates of the empirical distributions for the preference parameters $\theta$ and $\eta$, which enables me to construct the corresponding bootstrap percentile confidence intervals. Figure 2 dislays the corresponding histograms. Table 2, panel $\mathrm{C}$, presents the results. As may be observed, both methods lead to essentially the same point estimates.

Robustness Check: Failure of Model-Implied Cointegration Under Postulated Homotheticity. The model implies a single long-run relationship between the logs of the nondurable goods, the stock of durable goods, and their relative price. Note that the case of homotheticity $\eta=1$ is a nested model. I show hereafter that imposing artificially this constraint empirically breaks down this long-run relationship. In detail, both BIC and HQ criteria suggest that the $2 \times 1$ vector $\left(\log c_{t}-\log d_{t}, \log q_{t}\right)^{\prime}$ follows a second-order vector autoregressive process, $\operatorname{VAR}(2)$. The lag length $p$ for the vector error-correction model (VECM) is thus $p=2-1=1$. The null hypothesis of zero cointegrating vector against the alternative of at least 1 cannot be accepted at 5\% significance level, using both Johansen's trace 

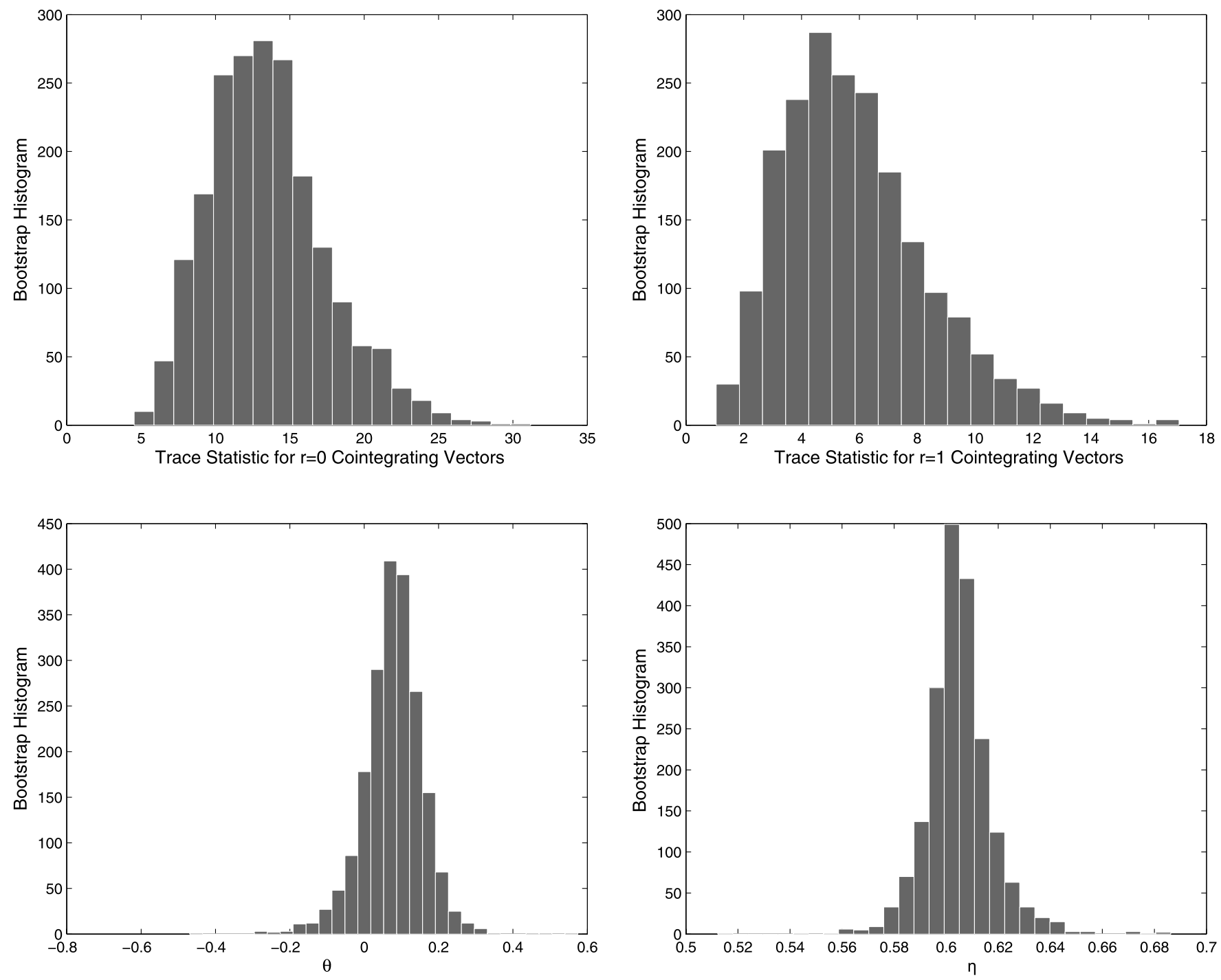

Figure 2. Histograms: Swensen's bootstrap. Notes: 2000 bootstrap experiments performed in Splus.

statistic $L R_{\text {trace }}$ and the Johansen's maximum eigenvalue statistic $L R_{\max }$. In detail, $L R_{\text {trace }}(0)=12.81<15.41=95 \%$ critical value, and $L R_{\max }(0)=8.36<14.07=95 \%$ critical value. In addition, the extremized log-likelihood function is about 1489.21, dramatically below 2458.18 obtained by not artificially forcing homotheticity on the data.

My model implies a single cointegrating long-run relationship. The fact that the empirical evidence in favor thereof is minimal in case of homothetic preferences indicates that artificially imposing the restriction of no income effects upon the relative demand function would lead to an outright rejection of the model.

Overall, it appears fair to conclude that there is an overwhelming evidence in favor of nonhomotheticity in the relative demand function for consumer durables.

Plausible Magnitude of the Parameter a: Implications of the Intratemporal First-Order Condition. Durable goods may be thought of as assets with the price $q_{t}$ paying a regular stream of rental costs $r c_{t}$. Note that $q_{t}$ is the "cum-dividend" price. To illuminate the analysis, define $p_{t}=q_{t}-r c_{t}$ as the "ex-dividend" price. The no-arbitrage condition

$$
r c_{t}=q_{t}-(1-\delta) \mathbb{E}_{t}\left\{m_{t+1} q_{t+1}\right\}
$$

may be expressed equivalently in the form more familiar from empirical finance as

$$
p_{t}=(1-\delta) \mathbb{E}_{t}\left\{m_{t+1}\left[p_{t+1}+r c_{t+1}\right]\right\}
$$

or

$$
1=\mathbb{E}_{t}\left\{m_{t+1}(1-\delta)\left[p_{t+1}+r c_{t+1}\right] / p_{t}\right\},
$$

where $m_{t+1}$ plays the role of the stochastic discount factor. The implied rate of return on the durable goods is then evidently

$$
R_{t+1}^{\text {durables }}=(1-\delta)\left(p_{t+1}+r c_{t+1}\right) / p_{t}
$$

and we obtain the familiar Euler equation

$$
\mathbb{E}_{t}\left[m_{t+1} R_{t+1}^{\text {durables }}\right]=1 \text {. }
$$

In order to make progress in constructing the rental cost of consumer durable goods, I make the following plausible assumption. 
Assumption 5. The risk premium on the durable goods, $R_{t+1}^{\text {durables }}-R_{t}^{f}$, is negligible (zero).

The following simple lemma is useful.

Lemma 6. The risk premium on durable goods is given by the formula

$$
\mathbb{E}_{t}\left[R_{t+1}^{\text {durables }}-R_{t}^{f}\right]=-R_{t}^{f} \times \operatorname{cov}_{t}\left[m_{t+1}, R_{t+1}^{\text {durables }}\right] .
$$

Proof. Straightforward using the definition of the conditional covariance

$$
\operatorname{cov}_{t}\left[X_{t+1}, Y_{t+1}\right]=\mathbb{E}_{t}\left[X_{t+1} Y_{t+1}\right]-\mathbb{E}_{t}\left[X_{t+1}\right] \mathbb{E}_{t}\left[Y_{t+1}\right]
$$

In view of Assumption 5 and Lemma 6, note that the rental cost price ratio satisfies

$$
\begin{aligned}
\frac{r c_{t}}{q_{t}}= & 1-(1-\delta) \mathbb{E}_{t}\left[m_{t+1}\left(\frac{q_{t+1}}{q_{t}}\right)\right] \\
= & 1-(1-\delta) \mathbb{E}_{t}\left[m_{t+1}\right] \mathbb{E}_{t}\left[\left(\frac{q_{t+1}}{q_{t}}\right)\right] \\
\approx & 1-(1-\delta)\left(R_{t}^{f}\right)^{-1} \exp \left(\mathbb{E}_{t}\left[\log \left(\frac{q_{t+1}}{q_{t}}\right)\right]\right) \\
& \times \exp \left(\frac{1}{2} \operatorname{var}_{t}\left[\log \left(\frac{q_{t+1}}{q_{t}}\right)\right]\right),
\end{aligned}
$$

where I invoke $\mathbb{E}_{t}\left[m_{t+1}\right]=\left(R_{t}^{f}\right)^{-1}$.

As shown in the subsection dealing with the Johansen's cointegration methodology, the vector time series $\left[\log c_{t}, \log d_{t}\right.$, $\left.\log q_{t}\right]^{\prime}$ follows a cointegrated $\operatorname{VAR}(2)$, and hence I estimate the corresponding vector error-correction model (see Table 2, panel B) to forecast the growth rate in the (log) durable goods price one quarter ahead, and consequently estimate the rental cost of consumer durable goods from the above formula. Empirically, it turns out that multivariate and univariate forecasts [from $\mathrm{AR}(1)$ ] are practically identical. In addition, I fit $\operatorname{GARCH}(1,1)$ model to the log of the durable goods price to model the variation in the conditional second moment. I perform several diagnostic checks. I test for the ARCH effects in the residuals. Then, I estimate $\operatorname{GARCH}(1,1)$ assuming a Gaussian distribution. Quantile-to-quantile plot for standarized residuals rejects this distributional assumption, and so does the Kolmogoroff-Smirnoff test. Hence, I assume that the errors come from the $t$ distribution, the degree of which is also estimated. Quantile-to-quantile plot supports this distributional assumption. Further results available upon request.

Subsequently, having constructed the rental-cost to price ratio from the above formula, I estimate the preference parameter $a>0$ from the intratemporal first-order condition

$$
\frac{a \times d_{t}^{-\eta / \theta}}{c_{t}^{-1 / \theta}}=r c_{t}
$$

as

$$
a=\frac{1}{T} \sum_{t=1}^{T} \frac{r c_{t} \times c_{t}^{-1 / \hat{\theta}}}{d_{t}^{-\hat{\eta} / \hat{\theta}}}
$$

where $\hat{\theta}$ and $\hat{\eta}$ are the superconsistent estimates. I find empirically that the parameter $a \approx 0.007$.
This back-of-the-envelope calculation of the magnitude of the parameter $a$ serves as an important check when I estimate the rest of the preference parameter vector $(\sigma, \beta, a)$ by the efficient method of moments.

\subsection{Estimation of the Rest of the Parameter Vector: Euler Equations Approach}

Methodology. My approach to the estimation and the inference of the rest of the preference parameter vector $\boldsymbol{\Theta}=$ $(\sigma, \beta, a) \in \mathbb{R}^{+} \times(0,1) \times \mathbb{R}^{+}$follows Ogaki and Reinhart (1998). These authors show how to modify the analysis of Hansen and Singleton (1982) to allow for multiple consumption goods. The primary testable asset pricing implications of the model are the set of intertemporal Euler equations

$$
\mathbb{E}_{t}\left[m_{t+1} R_{i, t+1}\right]=1,
$$

where $m_{t+1}$ is the intertemporal marginal rate of substitution,

$$
m_{t+1}=\frac{\beta U_{c}\left(c_{t+1}, d_{t+1}\right)}{U_{c}\left(c_{t}, d_{t}\right)}
$$

and $R_{i, t+1}$ is the gross return on an asset $i$.

In addition, we have the intratemporal first-order condition (2.5). Recall from the previous section that the cointegrating regression yields superconsistent estimates for parameters $\theta$ and $\eta$ but does not pin down the preference weight $a$ that enters the formula (2.5). Therefore, it is essential to include the intratemporal first-order condition in the GMM estimation, that is, to include

$$
\mathbb{E}_{t}\left\{U_{d t} /\left(q_{t} U_{c t}\right)-\left(r c_{t} / q_{t}\right)\right\}=0,
$$

where

$$
r c_{t}=q_{t}-(1-\delta) \mathbb{E}_{t}\left\{m_{t+1} q_{t+1}\right\}
$$

Let $\mathbf{z}_{t}$ be a vector of variables in the consumers' information set at time $t$. Using the components of $\mathbf{z}_{t}$ as instruments, I form the vector-valued function

$$
g_{T}(\boldsymbol{\Theta}) \triangleq \mathbb{E}_{T}\left\{\left[\begin{array}{c}
m_{t+1} R_{i, t+1}-1 \\
U_{d t} /\left(q_{t} U_{c t}\right)-\left(r c_{t} / q_{t}\right)
\end{array}\right] \otimes \mathbf{z}_{t}\right\}
$$

and use the Hansen's (1982) notation $\mathbb{E}_{T} \triangleq T^{-1} \sum_{t=1}^{T}$.

I calibrate the parameters $\theta$ and $\eta$ using the super-consistent estimates obtained by the cointegration approach as $\hat{\theta}=0.082$ and $\hat{\eta}=0.604$. I estimate the rest of the preference parameter vector $\widehat{\boldsymbol{\Theta}}$ by the choice of $\boldsymbol{\Theta}$ that makes the sample moment condition $g_{T}(\boldsymbol{\Theta})$ close to zero in the sense of minimizing the quadratic form

$$
\widehat{\boldsymbol{\Theta}}=\arg \min _{\boldsymbol{\Theta} \in \mathbb{R}_{+}^{3}} g_{T}^{\prime}(\boldsymbol{\Theta}) \widehat{\mathbf{S}}_{T}^{-1} g_{T}(\boldsymbol{\Theta}),
$$

where $\widehat{\mathbf{S}}_{T}$ is the spectral density matrix at frequency zero, estimated using quadratic spectral kernel with automatic bandwidth selection and VAR(1) prewhitening. I use the two-step version of the efficient GMM (Hansen 1982).

In my analysis I consider several instrumental variables. First, I use the lagged nondurable consumption growth rate, the lagged growth rate of the stock of durable goods, and the lagged growth rate in the durables price. These are lagged at least twice 
Table 3. GMM results

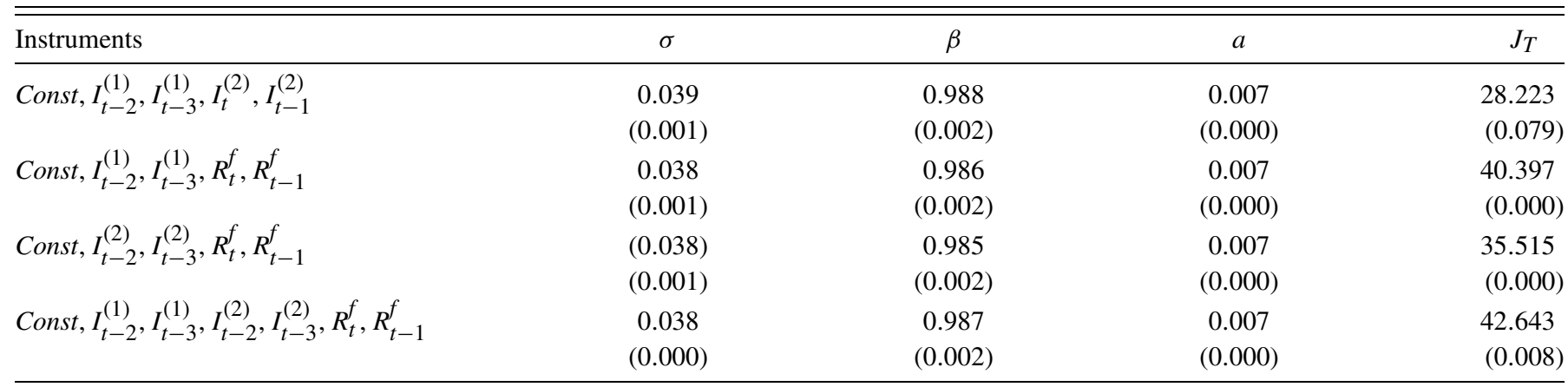

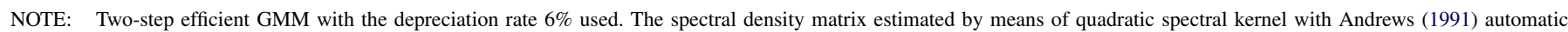

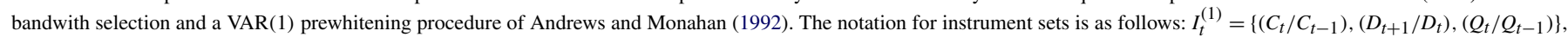

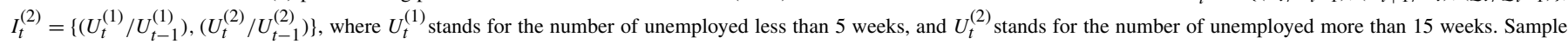
size 1951:I-2001:IV. HAC standard errors and $p$-values in parentheses.

to take care of the cash-in-advance constraint inherent in explicitly monetary models (see also Ogaki and Reinhart 1998). Secondly, a natural choice for the instrumental variables are both the growth rate of the number of civilians unemployed less than 5 weeks and the growth rate of the number of civilians unemployed more or equal 15 weeks. Finally, I also use the lagged real return on the U.S. Treasury Bills itself as an instrument.

Interpretation of the Empirical Results. Table 3 presents the GMM estimates for four different sets of instruments when the test asset is the U.S. Treasury Bill. The subjective discount factor $\beta$ is estimated around 0.986 . The estimate is also quite precise, and I am easily able to reject the hypothesis $H_{0}: \beta \geq 1$.

The parameter $a$ is estimated to be 0.007 . The point estimate is also quite precise, with the asymptotic standard error less than 0.001 . Note that the point estimate obtained from the efficient method of moments coincides with the back-of-theenvelope calculation based purely on the intratemporal firstorder condition as described in a subsection above. Figure 3 plots the combinations of the true preference weight $\tilde{a}$ and the household productivity $A$ which are consistent with $a=0.007$. For example, if the productivity $A=1.5$, consumer durable goods have about $10 \%$ weight in the households' preferences.

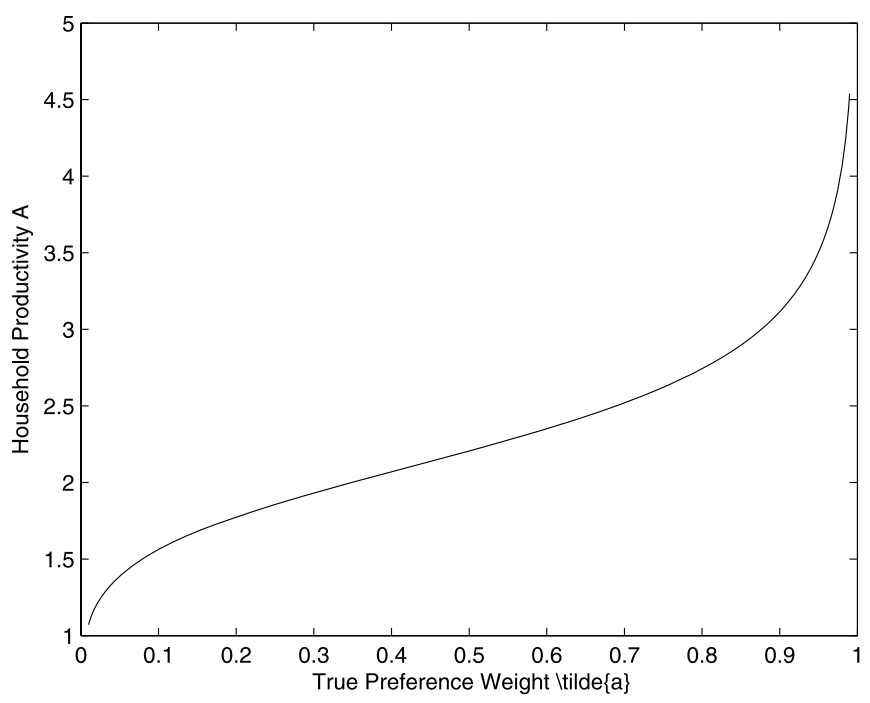

Figure 3. Implied preference weight and household productivity.
The preference parameter $\sigma$ is estimated from 0.038 up to 0.039 , and statistically significant although economically small. Again, the asymptotic standard error is quite small.

The test of the over-identifying restriction statistically rejects the model, except for the first row in Table 3. However, it is well known that asymptotic normality may provide a rather poor approximation to the sampling distribution of GMM estimators (Tauchen 1986; Kocherlakota 1990; West and Wilcox 1994; Hansen, Heaton, and Yaron 1996). For example, the sampling distribution of GMM estimators can be skewed and can have heavy tails, and tests of overidentifying restrictions can exhibit substantial size distortions. To check the robustness of my results, I follow Hall and Horowitz (1996) who develop a smallsample bootstrap approximations to the distributions of GMM estimators.

Robustness Check: Hall and Horowitz (1996) Bootstrap. Due to a quite high computational burden, I perform only 1000 bootstrap experiments, focusing only on the last row of Table 3. The $95 \%$ quantile of the empirical distribution comes about 54.73 , which is greater than the corresponding $J_{T}$ statistic of about 42.64 , and hence the model is not statistically rejected. I conclude that the asymptotic Gaussian distribution provides a rather poor approximation to the true sampling distribution of the $J_{T}$ statistic.

Robustness Check: Depreciation Rate of the Durable Goods. Yogo (2006) in his empirical study carefully constructs the stock of durable goods so that the annual stock equals exactly the estimate of the BEA. He consequently finds that the implied depreciation rate is about, but not exactly, $6 \%$.

I estimate the model assuming the depreciation rate equals $5.5 \%$ and $6.5 \%$. The results are presented in Table 4, panels A and $\mathrm{B}$, respectively. It is to be noted that the point estimates change minimally from the results in Table 3 . I therefore conclude that the statistical analysis is robust to economically relevant variation in the depreciation rate.

Robustness Check: Test Assets. As a further robustness check, I also include the real value-weighted return of all NYSE, AMEX, and NASDAQ stocks. Table 4, panel C, presents the GMM estimates when the only test asset is the market return. The point estimates of the parameter vector $(\sigma, \beta, a)$ are not statistically different from the estimates in Table 3. Finally, I include both the three-month Treasury Bill and the market return. As may be observed from Table 4, panel D, the point estimates again do not differ statistically from Table 3 . 
Table 4. GMM: robustness check

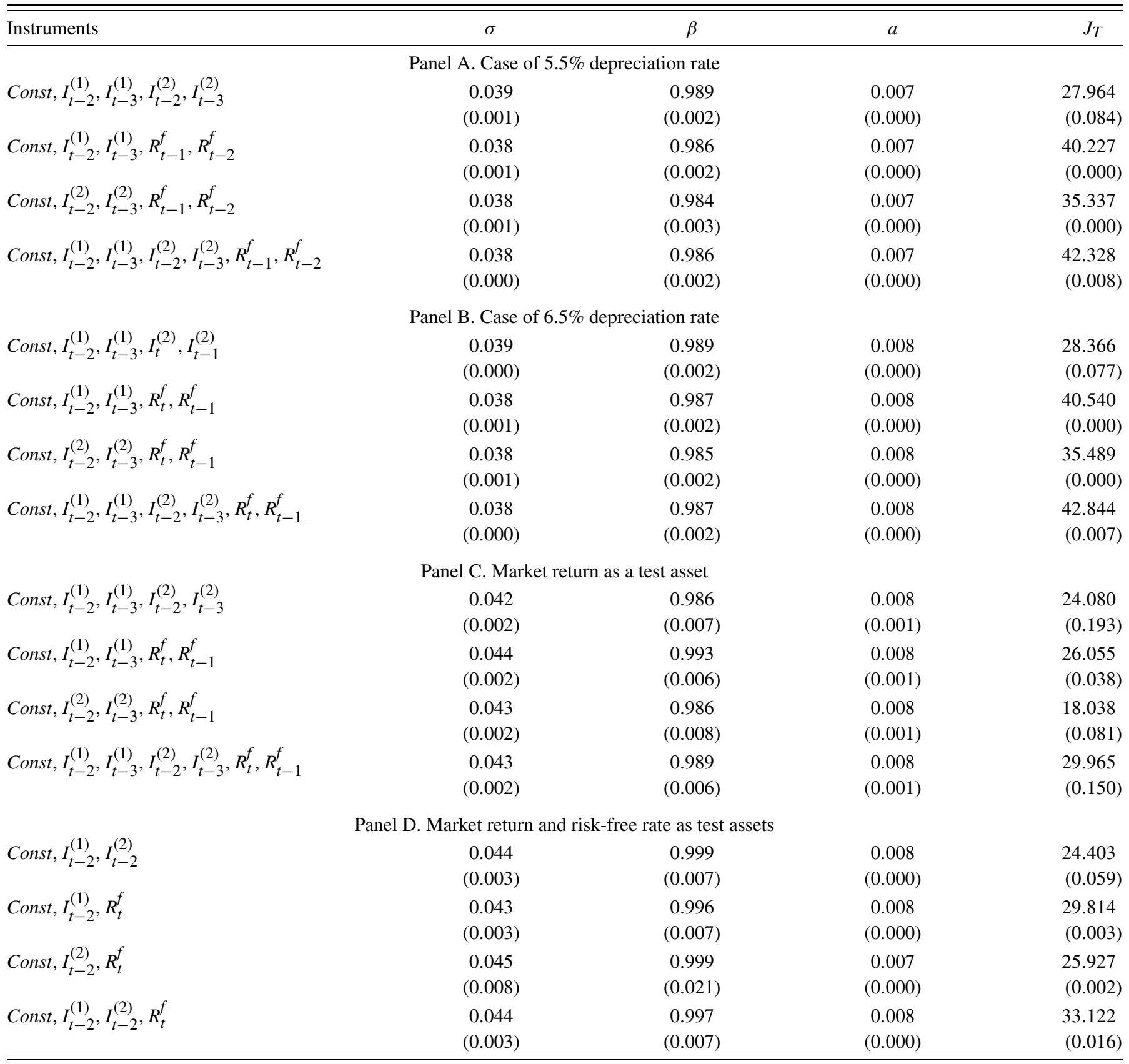

NOTE: Depreciation rate $6.0 \%$ used in panels $\mathrm{C}$ and $\mathrm{D}$. See also notes for Table 3.

\section{THE BUDGET SHARE, THE RENTAL COST AND THE EXPENDITURE ELASTICITY OF DURABLE GOODS}

Table 3, last row, allows me to construct the time series of (i) the implied rental cost of consumer durables $r c_{t}$, (ii) the budget share of the durable goods expenditures $s_{d, t}$ in total expenditures $e_{t}=c_{t}+r c_{t} \times d_{t}$, and (iii) the nondurables and the durables expenditure elasticities $\eta_{c, t}$ and $\eta_{d, t}$. First, I construct the implied rental cost of durables as the intratemporal marginal rate of substitution between the service flow from durable goods and nondurable goods,

$$
r c_{t}=\frac{U_{d}\left(c_{t}, d_{t}\right)}{U_{c}\left(c_{t}, d_{t}\right)} .
$$

It is displayed in Figure 4, left panel. Empirically, it turns out that the rental cost is between $3.18 \%$ to $11.74 \%$ of the durable goods price per quarter, depending on the exact date, which appears to be a plausible magnitude. Furthermore, the model implies, and the econometric analysis further confirms that the ratio $r c_{t} / q_{t}$ is stationary, and hence both the real rental cost $r c_{t}$ and the real durables price $q_{t}$ decline secularly in the post-war U.S. economy (see also Figure 1). This has an essential implication for the budget share of durable goods $s_{d, t}$, which in fact appear trendless, despite the fact that durable goods are luxury goods. Formally, one may easily show by log-differentiating the definition formula for the budget share $s_{d, t}$ that

$$
d \log s_{d, t}=\left(1+\varepsilon_{d d, t}\right) \times d \log r c_{t}+\left(\eta_{d, t}-1\right) \times d \log e_{t} .
$$



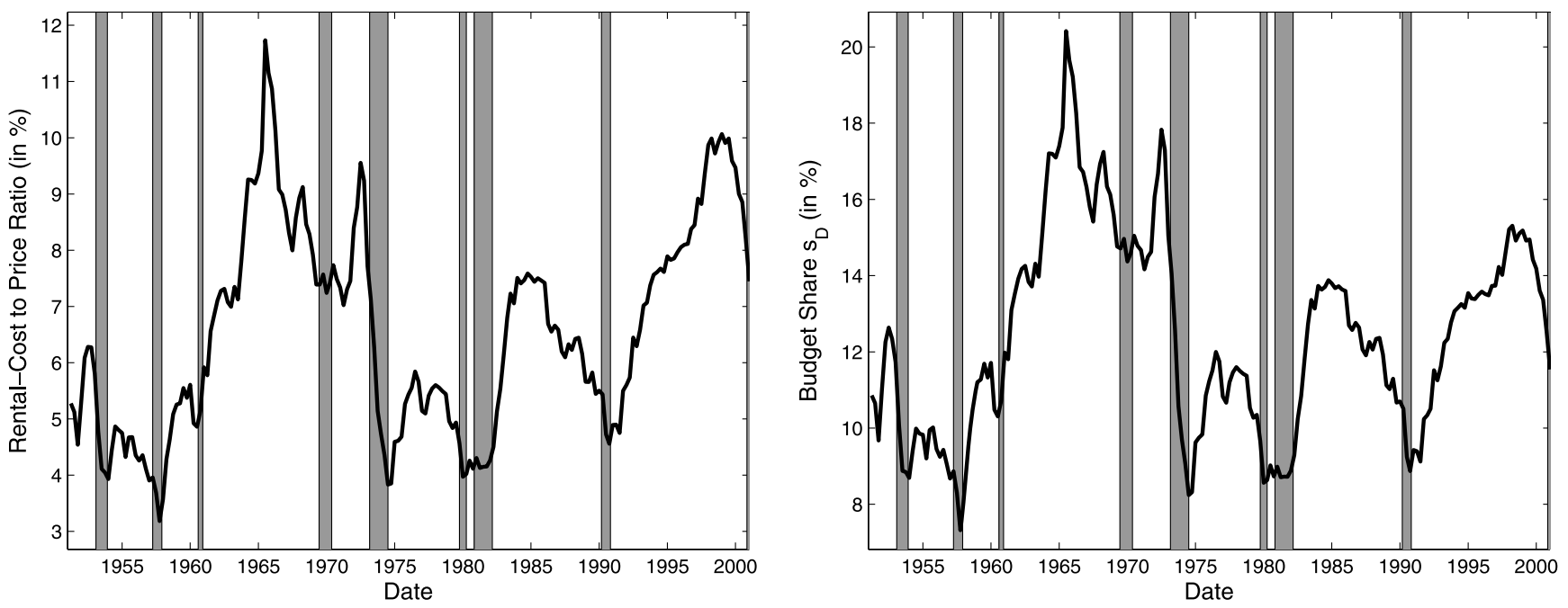

Figure 4. Historical time series of the rental cost of consumer durable goods and the corresponding budget share. Notes: Bars represent NBER recessions. Sample size 1951:I-2001:IV.

Back of the envelope calculation, along with the Slutsky equation $\varepsilon_{d d, t}=\varepsilon_{d d, t}^{*}-s_{d, t} \times \eta_{d, t}$, suggest that indeed the budget share of durable goods appears trendless over time (see also Figure 4, right panel).

In detail, the Marshallian price elasticity $\varepsilon_{d d, t}$ is small and negative. First, the Hicksian price elasticity $\varepsilon_{d d, t}^{*}$ is small and negative. Durable goods do not have easy substitutes and, in addition, the substitution matrix is negative semidefinite and hence all diagonal terms are nonpositive. Second, all consumption goods categories in the model are normal, with expenditure elasticities positive. Third, the budget share of durable goods is relatively small, and, hence, the term $\left(1+\varepsilon_{d d, t}\right) \approx 1$. The term $\left(\eta_{d, t}-1\right) \approx 0.5$, which is less than one. This suggests, and Figure 4 confirms empirically, that despite the nonhomotheticity and the secular increase in the total consumption expenditures (i.e., $d \log e_{t}>0$ ), the budget share of durable goods appears trendless precisely because the rental cost of durables declines so steeply, that is, $d \log r c_{t} \ll 0$, fully offsetting the corresponding income effect.

The intraperiod budget constraint implies that the weighted average of expenditure elasticities must be one

$$
s_{c, t} \times \eta_{c, t}+s_{d, t} \times \eta_{d, t}=1,
$$

where $s_{c, t}$ and $s_{d, t}$ are the shares of nondurables and durables, respectively, in total within-period consumption expenditures $e_{t}=c_{t}+r c_{t} \times d_{t}$. I find that $\eta_{d} \in[1.460,1.579]$ and $\eta_{c} \in$ [0.882, 0.954]; see also Figure 5, bottom two panels. Evidently, durable goods are luxury goods and nondurable goods are necessary goods.

\section{THE INTRATEMPORAL ELASTICITY OF SUBSTITUTION ES}

Although it is tempting to refer to the preference parameter $\theta$ as a yardstick of the intratemporal substitutability, its true measure is given by the relationship $E S=\theta+\varepsilon_{d d}^{*} \times(\eta-1)$, where $\varepsilon_{d d}^{*}$ is the Hicksian own-price elasticity of the demand for the service flow of durable goods. Figure 5, top left panel, portrays the estimated time-series of the elasticity of the intratemporal substitution ES, which lies in the interval of [0.172, 0.194].

\section{THE INTERTEMPORAL ELASTICITY OF SUBSTITUTION IES}

The elasticity of intertemporal substitution IES is an essential input into many dynamic macroeconomic models. Because the preference specification features nonhomotheticity, the elasticity of intertemporal substitution EIS does not equal the parameter $\sigma$ exactly as is the case under homotheticity. In fact, EIS tells how much the total consumption expenditure, or the saving, if you like, changes in response to predictable changes in the real interest rate. Appendix E shows that, under deterministic setup, the intratemporal first-order condition is a solution of the second-stage of two-stage budgeting, and the indirect felicity function $V(e, r c)$ is the value function of the following concave program

$$
V(e, r c)=\max _{\left\{(c, d) \in R_{+}^{2}\right\}} U[C(c, d)]
$$

subject to the budget constraint

$$
c+r c \times d \leq e,
$$

where $e$ is the total consumption expenditure within the period and $r c$ is the rental cost of consumer durables.

Following Atkeson and Ogaki (1996), I define the intertemporal elasticity of substitution IES as the inverse of the elasticity of the marginal utility $V_{e}(e, r c)$ of the total consumption expenditures $e$,

$$
\begin{aligned}
\text { IES } & =-\left(\frac{\partial \log V_{e}(e, r c)}{\partial \log e}\right)^{-1} \\
& =-\frac{V_{e}(e, r c)}{e \times V_{e e}(e, r c)} .
\end{aligned}
$$

Intuitively, suppose the elasticity of the marginal utility $V_{e}$ of the total consumption expenditures $e$ is large. That means that a small change in $e$ leads to a large change in the corresponding marginal utility $V_{e}$. Because consumers strive to spread their consumption expenditures $e$ over time, depending on their forecasts of the real interest rate, in order to maximize their welfare, 
Panel A. Historical time series of the intratemporal and intertemporal elasticities of substitution.
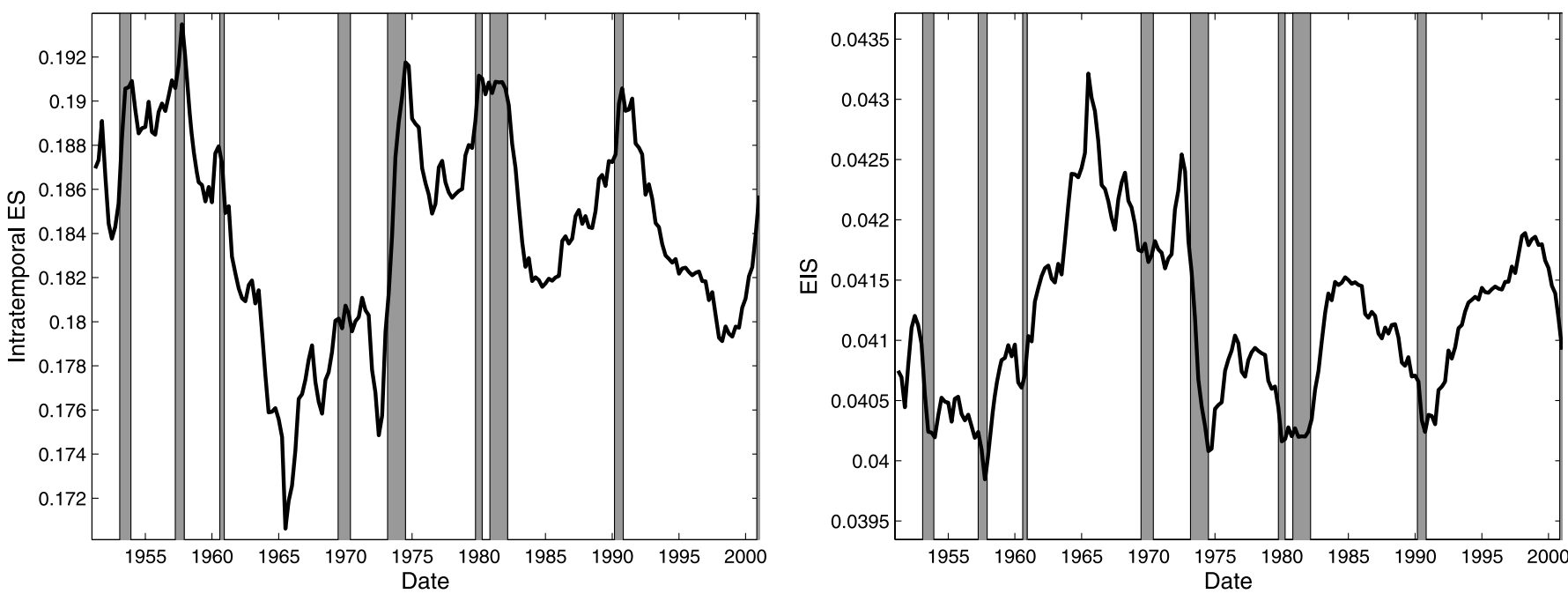

Panel B. Historical time series of the expenditure elasticities
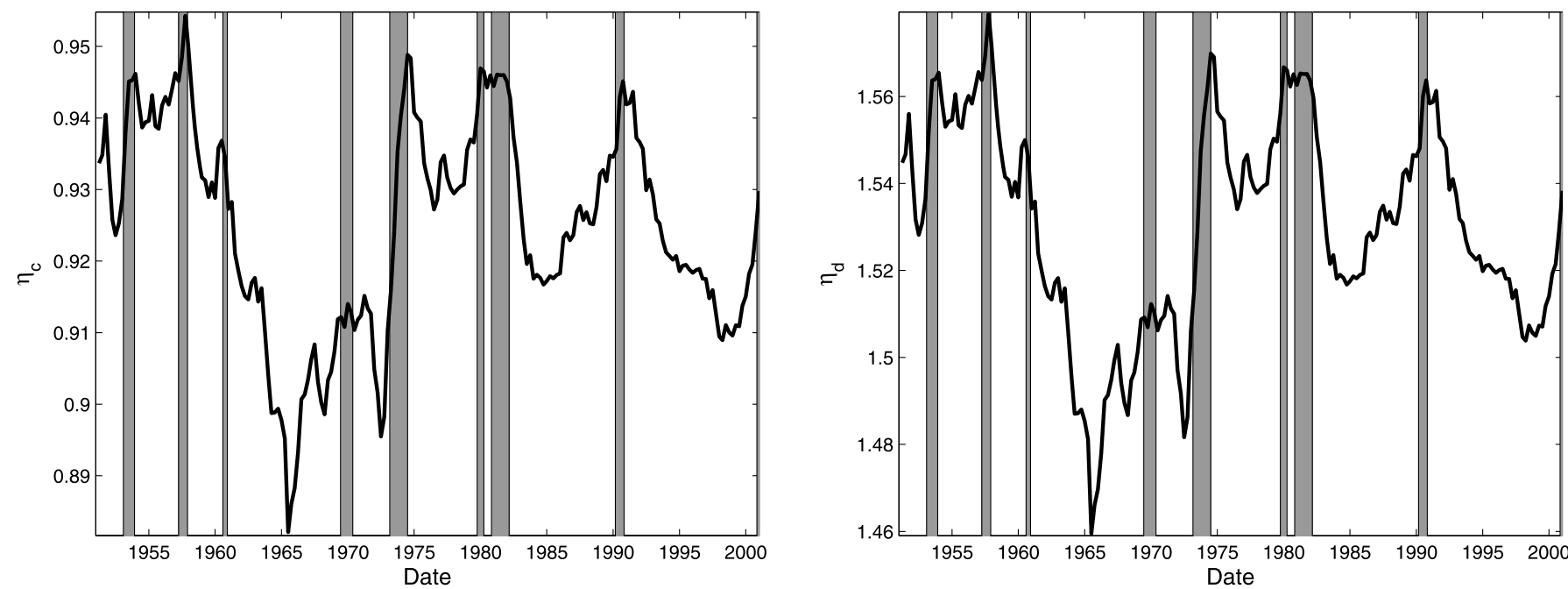

Figure 5. Estimated elasticities. Notes: Bars represent NBER recessions. Sample size 1951:I-2001:IV.

they will alter their spending plans minimally; otherwise, there will be a dramatic variation in marginal utility $V_{e}$ across time that cannot be possibly optimal. As a result, the intertemporal elasticity of substitution IES is small and a predictable change in the real interest rate will give occasion to a relatively small change in the consumption expenditures $e$.

As the preferences are nonhomothetic, a closed-form solution for $V(e, r c)$ may not exist. However, a numerical solution, described in Appendix E, is rather straightforward. See Hanoch (1977) for a different treatment.

Figure 5 portrays the time-series of the estimated IES for the preference parameter calibrations based on the super-consistent estimates from the intratemporal first-order condition and the GMM estimates from Table 3, row 4. As may be observed, the IES is economically negligible.

The economically inconsequential magnitude of the IES for the total consumption expenditures makes intuitive sense. In fact, the budget share of durable goods is only about $7.32 \%-20.41 \%$. As the bulk of consumption is composed predominantly of nondurable goods with practically zero IES
(Hall 1988), it comes as no surprise to discover that considering durable goods that themselves in fact do have high IES (Mankiw 1982) does not raise the overall IES for the total consumption. The time-variation in the IES is a direct consequence of the preference nonhomotheticity.

\section{CONCLUSION}

This paper argues that ignoring the income effects (nonhomotheticity) in the relative demand function for durable goods induces a striking bias in the estimates of the magnitude of the intertemporal and intratemporal substitutions. When I correct for nonhomotheticity, I find the magnitude of the elasticity of intertemporal substitution EIS to be small, on the order of magnitude 0.04. In addition, I find compelling evidence against the separability across consumption goods in the felicity function. However, in contrast to Eichenbaum and Hansen's (1990) value of 0.91 and Ogaki and Reinhart's (1998) value greater than one, my estimate of the elasticity of intratemporal substitution, after careful correction for nonhomotheticity, is around 0.18. Last, 
I have found strong evidence in favor of nonhomotheticity in the aggregate consumption data. Nondurable consumption is a necessary good and the service flow from durables is a luxury good, with the within-period expenditure elasticity greater than one. This is consistent with the results in Ogaki (1992) and Costa (2001).

\section{APPENDIX A: IDENTIFICATION AND BACK OF THE ENVELOPE CALCULATION OF THE PLAUSIBLE VALUES OF THE PREFERENCE PARAMETER $a$}

In the empirical part, I reparametrize the consumption index so that all the parameters are identified. For example, we cannot separately identify the preference weight $\tilde{a}$ and the coefficient $A$ from the household production function. In detail, suppose we keep the parametrization of the consumption index as

$$
C(c, d)=\left\{(1-\tilde{a}) c^{1-1 / \theta}+\tilde{a}(A \times d)^{1-\eta / \theta}\right\}^{\theta /(\theta-1)} .
$$

Clearly, $\tilde{a} \in(0,1)$ and $A \in \mathbb{R}^{+}$. "Taking out" the number $1-\tilde{a}$ from the consumption index, and rearranging the terms yields

$$
C(c, d)=(1-\tilde{a})^{\theta /(\theta-1)}\left\{c^{1-1 / \theta}+\frac{\tilde{a} A^{1-\eta / \theta}}{1-\tilde{a}} d^{1-\eta / \theta}\right\}^{\theta /(\theta-1)}
$$

Because applying a strictly increasing operator (i.e., multiplying by a positive number in our case) does not change the preference ordering, I may drop the term $(1-\tilde{a})^{\theta /(\theta-1)}$. In addition, I denote

$$
a=\frac{\tilde{a} A^{1-\eta / \theta}}{1-\tilde{a}}
$$

to obtain

$$
C(c, d)=\left\{c^{1-1 / \theta}+a \times d^{1-\eta / \theta}\right\}^{\theta /(\theta-1)},
$$

the preference specification that I actually use in the GMM estimation.

There is a deep reason for using this "simpler" consumption index (A.4). In fact, as may be easily inferred from the analysis above, the indices (A.1) and (A.4) are observationally equivalent and generate exactly the same preference orderings. However, as econometricians, we clearly cannot separately identify the preference weight $\tilde{a}$ and the household production function coefficient $A$; only the parameter $a$ is econometrically identified. Unfortunately, a hurried reader tends to have a strong prior on the plausible magnitudes of the parameter $a$, which seemingly looks like a preference weight, and thus wrongly expects magnitudes $a \in(0,1)$.

\section{APPENDIX B: PROOF OF PROPOSITION 2}

First, in order to work with linear time series, I follow Campbell and Shiller (1988), and log-linearize the log of the intertemporal marginal rate of substitution. In detail, the first-order approximation of the function $F(x)=\log [1+\exp (x)]$ around a point $\bar{x}$ is

$$
\begin{aligned}
F(x) & \approx F(\bar{x})+F^{\prime}(\bar{x})(x-\bar{x}) \\
& \approx \log [1+\exp (\bar{x})]+\frac{\exp (\bar{x})}{1+\exp (\bar{x})}(x-\bar{x})
\end{aligned}
$$

$\propto k x$.
As a result, the $\log$ of $f_{t}$ is approximately

$$
\log f_{t} \approx k\left[\left(1-\frac{\eta}{\theta}\right) \log d_{t}+\left(1-\frac{1}{\theta}\right) \log c_{t}\right] .
$$

Recall that the (log) intertemporal marginal rate of substition $m_{t+1}$ is defined as

$$
\begin{aligned}
\log m_{t+1} \propto & \left(-\frac{1}{\sigma}\right)(1-L) \log c_{t}-\frac{\theta-\sigma}{\sigma(\theta-1)}(1-L) \log f_{t} \\
\propto & \left(-\frac{1}{\sigma}\right)(1-L) \log c_{t} \\
& -\frac{k(\theta-\sigma)}{\sigma(\theta-1)}(1-L) \\
& \times\left[\left(1-\frac{\eta}{\theta}\right) \log d_{t}+\left(1-\frac{1}{\theta}\right) \log c_{t}\right],
\end{aligned}
$$

where $L$ is the lag, or backshift, operator. According to Assumption 1 , all terms are covariance stationary as they involve growth rates of $I(1)$ variables.

\section{APPENDIX C: PROOF OF PROPOSITION 3}

Equilibrium requires a lack of arbitrage in all markets, including the market for durable goods. The no-arbitrage condition in the goods market is embodied in the following condition:

$$
r c_{t}=q_{t}-(1-\delta) \mathbb{E}_{t}\left[m_{t+1} q_{t+1}\right]
$$

as explained in the main text. I shall prove the existence of a single long-run relationship between $\log r c_{t}$ and $\log q_{t}$ by following Campbell and Shiller (1988). Note that durable goods price to rental cost is the exact analogue to the price-dividend ratio in the model of common stocks. In detail, rearranging the previous no-arbitrage condition yields

$$
\begin{aligned}
\log \left(1-\frac{r c_{t}}{q_{t}}\right) & =\log (1-\delta)+\log \mathbb{E}_{t}\left[m_{t+1} q_{t+1} / q_{t}\right] \\
& \propto \log \mathbb{E}_{t}\left[\exp \left\{\log m_{t+1}+\log \left(q / q_{t}\right)\right\}\right] \\
& \propto \mathbb{E}_{t}\left[\log m_{t+1}+\log \left(q_{t+1} / q_{t}\right)\right],
\end{aligned}
$$

where I assumed in the last step that the time series is Gaussian as not much is known about nonlinear time series.

According to Assumption 1, the log-durable goods price $\log q_{t} \sim I(1)$, and according to Proposition $2 \log m_{t+1} \sim I(0)$. Define the $4 \times 1$ vector

$$
\boldsymbol{\xi}_{t}=\left[(1-L) \log c_{t},(1-L) \log d_{t},(1-L) \log q_{t}, \log m_{t}\right]^{\prime} .
$$

Wold representation theorem (e.g., Brockwell and Davis 1991, p. 187) says that the stochastic process $\boldsymbol{\xi}_{t}$ has $\mathrm{MA}(\infty)$ representation as follows:

$$
\boldsymbol{\xi}_{t}=\boldsymbol{\mu}+\boldsymbol{\Psi}(L) \boldsymbol{\varepsilon}_{t}=\boldsymbol{\mu}+\sum_{j \in \mathbb{N}} \boldsymbol{\Psi}_{j} \boldsymbol{\varepsilon}_{t-j},
$$

where $\boldsymbol{\varepsilon}_{t} \sim \mathrm{WN}\left(0, \Omega_{\boldsymbol{\varepsilon}}\right)$, a white noise, and $\left\{\boldsymbol{\Psi}_{j}\right\}_{j \in \mathbb{N}}$ is a square summable matrix series. I assume that the forecast errors $\boldsymbol{\varepsilon}_{t}$ are Gaussian. In addition, I invoke the following simple lemma.

Lemma 7. Let the filtration $\left\{\mathcal{F}_{t}\right\}_{t \in \mathbb{N}}$ be defined as $\mathcal{F}_{t}=$ $\sigma\left(\left\{c_{s}, d_{s}, q_{s}: 0 \leq s \leq t\right\}\right)$. Then, the stochastic process $\left\{\mathbb{E}\left(\boldsymbol{\xi}_{t+1} \mid \mathcal{F}_{t}\right)\right\}_{t \in \mathbb{N}}$ is a covariance stationary process. 
Proof. Direct calculation shows that

$$
\mathbb{E}\left(\boldsymbol{\xi}_{t+1} \mid \mathcal{F}_{t}\right)=\boldsymbol{\mu}+\sum_{j \in \mathbb{N}} \boldsymbol{\Psi}_{j+1} \boldsymbol{\varepsilon}_{t-j}
$$

and that the matrix series $\left\{\boldsymbol{\Psi}_{j+1}\right\}_{j \in \mathbb{N}}$ is square summable as $\left\{\boldsymbol{\Psi}_{j}\right\}_{j \in \mathbb{N}}$ itself is.

In view of this, we have that

$$
\log \left(1-\frac{r c_{t}}{q_{t}}\right)=[0,0,1,1] \times \mathbb{E}_{t}\left[\xi_{t+1}\right] \sim I(0) .
$$

Finally, log-linearize, following Campbell and Shiller (1988) the relationship $\log \left(1-\frac{r c_{t}}{q_{t}}\right)$ by defining $x_{t}=\log \left(r c_{t} / q_{t}\right)$

$$
\log \left(1-\exp \left\{x_{t}\right\}\right) \approx \log [1-\exp (\bar{x})]-\frac{\exp (\bar{x})}{1-\exp (\bar{x})}(x-\bar{x}) .
$$

This analysis shows that $\log r c_{t}-\log q_{t} \approx[0,0,1,1] \times$ $\mathbb{E}_{t}\left[\xi_{t+1}\right] \sim I(0)$. Hence, the model implies a single cointegrating vector $[1,-1]$.

\section{APPENDIX D: INTERPRETATION OF THE PREFERENCE PARAMETERS IN A DETERMINISTIC SETUP}

The preference parameters $\theta$ and $\eta$ are most easily interpreted in the deterministic setup. Let us think of consumers as renting their stock of durables $d_{t}$ in a perfect rental market, with the rental cost $r c_{t}$ given by the right-hand side of equation (2.5), namely,

$$
r c_{t}=q_{t}-(1-\delta) E_{t}\left\{m_{t+1} q_{t+1}\right\} .
$$

In a deterministic setup, the risk-free interest rate $1+r_{t}^{f}=m_{t+1}^{-1}$ and the rental cost of capital satisfies $r c_{t}=q_{t}-(1-\delta)(1+$ $\left.r_{t}^{f}\right)^{-1} q_{t+1}$. Viewed this way, the preferences over nondurables and durables are weakly separable. Weak separability is a necessary and a sufficient condition for the second-stage of twostage budgeting to hold (Deaton and Muellbauer 1980). Intuitively, suppose the consumer has already chosen his optimal within-period $t$ total consumption expenditure $e_{t}$, expressed in terms of nondurable consumption, which is a numeraire throughout unless stated otherwise. The level of the nondurable consumption $c_{t}$ and the stock of durable goods to be rented $d_{t}$ are then chosen so that the second-stage optimization holds, formally,

$$
\left(c_{t}, d_{t}\right)=\arg \max _{\left\{\left(\tilde{c}_{t}, \tilde{d}_{t}\right) \in R_{+}^{2}\right\}} U\left[C\left(\tilde{c}_{t}, \tilde{d}_{t}\right)\right]
$$

subject to the budget constraint

$$
\tilde{c}_{t}+r c_{t} \times \tilde{d}_{t} \leq e_{t}
$$

Note that the expenditures $e_{t}$ in other periods $t$ are unaffected and the consumer thereby maximizes his lifetime well being.

The first-order condition associated with the second stage is helpful to interpret the preference parameters. The Marshallian demands are functions of the relative price $r c_{t}$ and the expenditure $e_{t}$,

$$
\begin{aligned}
c_{t} & =c\left(r c_{t}, e_{t}\right), \\
d_{t} & =d\left(r c_{t}, e_{t}\right) .
\end{aligned}
$$

Log-differentiating yields

$$
\begin{aligned}
& d \log c_{t}=\varepsilon_{c d} \times d \log r c_{t}+\eta_{c} \times d \log e_{t}, \\
& d \log d_{t}=\varepsilon_{d d} \times d \log r c_{t}+\eta_{d} \times d \log e_{t} .
\end{aligned}
$$

The parameters $\eta_{c}$ and $\eta_{d}$ are the expenditure elasticities associated with the within-period $t$ expenditure level $e_{t}$. They tell us how much the demands $c_{t}$ and $d_{t}$ change (in percentage terms) in response to a $1 \%$ rise in the total within-period $t$ expenditure level $e_{t}$, ceteris paribus. Formally, they are defined as percentage changes in the Marshallian demands in response to a percentage change in expenditures, $\eta_{c}=\partial \log c_{t} / \partial \log e_{t}$ and $\eta_{d}=\partial \log d_{t} / \partial \log e_{t}$. The budget constraint (D.3) implies that the weighted average of these elasticities must be one. The parameters $\varepsilon_{c d}$ and $\varepsilon_{d d}$ are Marshallian price elasticities. Subtracting one equation from the other, using Slutsky equation $\varepsilon_{i j}=\varepsilon_{i j}^{*}-\eta_{i} s_{j}$, where $s_{j}$ is the share of $\operatorname{good} j \in\{c, d\}$ in expenditures $e_{t}$, and $\varepsilon_{i j}^{*}$ is the compensated Hicksian price elasticity, implies that the relative demand function satisfies

$$
d \log \left(c_{t} / d_{t}\right)=\underbrace{E S \times d \log r c_{t}}_{\text {substitution effect }}+\underbrace{\left(\eta_{c}-\eta_{d}\right) \times d \log \hat{e}_{t}}_{\text {income effect }},
$$

where $E S \equiv \varepsilon_{c d}^{*}-\varepsilon_{d d}^{*}$ denotes the elasticity of intratemporal substitution (see the discussion below). The variable $e_{t}$ is the expenditure on both consumption goods, expressed in terms of nondurable goods whereas what I call the real expenditure $\hat{e}_{t}$ is expressed in terms of the composite good, with the implicitly defined price index. In fact, it is defined as $d \log \hat{e}_{t}=d \log e_{t}-$ $s_{d} d \log r c_{t}$. The appropriate price index is $p_{t}=1^{s_{c}} \times r c_{t}^{s_{d}}$, and hence the real expenditure satisfies $d \log \hat{e}_{t}=d \log \left(e_{t} / p_{t}\right)$.

The elasticity of substitution ES is defined as a percentage change in the relative Hicksian demand in response to a percentage change in the relative price,

$$
E S=\partial \log \left(c_{t}^{*} / d_{t}^{*}\right) / \partial \log r c_{t}=\varepsilon_{c d}^{*}-\varepsilon_{d d}^{*}
$$

and it is a measure of the concavity of the indifference curves. For instance, $E S=0$ for Leontief preferences and thus the indifference curves are extremely concave. It may be shown by combining the equations in this appendix that

$$
E S=\theta+\varepsilon_{d d}^{*} \times(\eta-1),
$$

where in anticipation of a future result, I define

$$
\begin{aligned}
& \theta=\left(\varepsilon_{c d}^{*}-\varepsilon_{d d}^{*} \eta\right), \\
& \eta=\eta_{c} / \eta_{d} .
\end{aligned}
$$

Based on a back of the envelope calculation, the parameter $\theta$ underestimates the true elasticity of intratemporal substitution ES. That is, $\varepsilon_{d d}^{*}$ is nonpositive because the substitution matrix is negative semidefinite, and the parameter $\eta$ is less than one, empirically. As a result,

$$
E S \geq \theta
$$

but I still refer to $\theta$ as a yardstick of intratemporal substitutability.

I now derive the deterministic equivalent of the intratemporal first-order condition. Eliminate the expenditure $e_{t}$ in the system of the Marshallian demands to get the conditional demand

$$
d \log c_{t}=\left(\varepsilon_{c d}^{*}-\varepsilon_{d d}^{*} \eta\right) \times d \log r c_{t}+\left(\frac{\eta_{c}}{\eta_{d}}\right) \times d \log d_{t}
$$


or, using the definition of $\theta$ and $\eta$ in equations (D.11) and (D.12),

$$
d \log c_{t}=\theta \times d \log r c_{t}+\eta \times d \log d_{t} .
$$

One may integrate the equation-the parameters $\theta$ and $\eta$ are constant - to obtain

$$
\log c_{t} \propto \theta \times \log r c_{t}+\eta \times \log d_{t} .
$$

Let us link the rental cost of durables $r c_{t}$ to the price of durables $q_{t}$

$$
\log r c_{t}=\log q_{t}+\log \left(1-E_{t}\left\{m_{t+1} \frac{q_{t+1}}{q_{t}}\right\}\right),
$$

where the second term on the right-hand side is assumed to be stationary to obtain the intratemporal first-order condition

$$
\log c_{t} \propto \theta \times \log q_{t}+\eta \times \log d_{t}+\text { error } .
$$

If stochastic setting is considered explicitly, all stochastic terms go into the error term.

\section{APPENDIX E: THE VALUE FUNCTION OF THE SECOND STAGE OF TWO STAGE BUDGETING}

In order to find the intertemporal elasticity of substitution EIS, one needs first to compute the value function $V(e, r c)$, that is, to solve the following optimization problem

$$
V\left(e_{t}, r c_{t}\right)=\max _{\left\{\left(c_{t}, d_{t}\right) \in R_{+}^{2}\right\}} U\left[C\left(c_{t}, d_{t}\right)\right]
$$

subject to the budget constraint

$$
c_{t}+r c_{t} \times d_{t} \leq e_{t} .
$$

The IES parameter is then defined (Atkeson and Ogaki 1996) as

$$
I E S=-\frac{\partial V(e, r c) / \partial e}{e \times \partial^{2} V(e, r c) / \partial e^{2}} .
$$

Technically, I substitute the budget constraint into the objective function and then use MATLAB function fminbnd applied to the minus of the objective function. I impose the constraints that $d>0$ and $d<e / r c$ so that the implied $c>0$. In addition, I construct the rental cost of consumer durable goods as

$$
r c_{t}=\frac{U_{d}\left(c_{t}, d_{t}\right)}{U_{c}\left(c_{t}, d_{t}\right)} .
$$

To evaluate the partial derivatives necessary to compute IES, I use the following finite-difference approximations

$$
\begin{aligned}
& \frac{\partial V(e, r c)}{\partial e} \\
& =\frac{V(e+\Delta e, r c)-V(e-\Delta e, r c)}{2 \times \Delta e}+O\left((\Delta e)^{2}\right), \\
& \frac{\partial^{2} V(e, r c)}{\partial e^{2}} \\
& =\frac{V(e+\Delta e, r c)-2 \times V(e, r c)+V(e-\Delta e, r c)}{(\Delta e)^{2}} \\
& \quad+O\left((\Delta e)^{2}\right),
\end{aligned}
$$

and I choose $\Delta e=10^{-5}$.

\section{ACKNOWLEDGMENTS}

This paper is an outgrowth of Chapter 1 of my Ph.D. Dissertation at the Graduate School of Business, University of Chicago. I am grateful for the advice and encouragement from my thesis committee: John Cochrane, John Heaton (chair), Monika Piazzesi, and Pietro Veronesi. My thanks also go to Professors Gary Becker and Kevin Murphy from whom I have learned so much. In addition, I have benefited from helpful comments by Peter Bossaerts, John Campbell, George Constantinides, George-Levi Gayle, Rick Green, Lior Menzly, Masao Ogaki, Jonathan Parker, Lukasz Pomorski, Ruy Ribeiro, Nick Roussanov, Sergei Sarkissian, Fallaw Sowell, Chris Telmer, Stan Zin, and the Editor, the anonymous Associate Editor in charge, and two anonymous referees. Research support from the Oscar Mayer Foundation is gratefully acknowledged; any opinions expressed herein are the author's and not necessarily those of the Oscar Mayer Foundation. Remaining errors are my own responsibility.

\section{[Received March 2007. Revised March 2009.]}

\section{REFERENCES}

Andrews, W. K. D. (1991), "Heteroskedasticity and Autocorrelation Consistent Covariance Matrix Estimation," Econometrica, 59 (3), 817-858.

Andrews, W. K. D., and Monahan, C. J. (1992), "An Improved Heteroskedasticity and Autocorrelation Consistent Covariance Matrix Estimator," Econometrica, 60 (4), 953-966.

Atkeson, A., and Ogaki, M. (1996), "Wealth Varying Intertemporal Elasticities of Substitution: Evidence From Panel and Aggregate Data," Journal of Monetary Economics, 38, 507-534.

Bernanke, S. B. (1984), "Permanent Income, Liquidity, and Expenditure on Automobiles: Evidence From Panel Data," Quarterly Journal of Economics, 99, 587-614.

Brockwell, P. J., and Davis, R. A. (1991), Time Series: Theory and Methods. Springer Series in Statistics, New York: Springer-Verlag.

Caballero, J. R. (1993), "Durable Goods: An Explanation for Their Slow Adjustment," Journal of Political Economy, 101, 351-384.

Campbell, J. Y. (1999), "Asset Prices, Consumption and the Business Cycle," in Handbook of Macroeconomics, Vol. 1, eds. J. B. Taylor and M. Woodford, Amsterdam: North-Holland, pp. 1231-1303, Chap. 19.

Campbell, J. Y., and Shiller, R. J. (1988), "Stock Prices, Earnings, and Expected Dividends," Journal of Finance, 43 (3), 661-676.

Cooley, F. T., and Ogaki, M. (1996), "A Time Series Analysis of Real Wages, Consumption, and Asset Returns," Journal of Applied Econometrics, 11, 119-134.

Costa, L. D. (2001), "Estimating Real Income in the United States From 1988 to 1994: Correcting CPI Bias Using Engel Curves," Journal of Political Economy, 109, 1288-1310.

Deaton, A., and Muellbauer, J. (1980), Economics and Consumer Behavior, Cambridge, U.K.: Cambridge University Press.

Dunn, K. B., and Singleton, K. J. (1986), "Modelling the Term Structure of Interest Rates Under Nonseparable Utility and Durability of Goods," Journal of Financial Economics, 17, 27-55.

Eberly, C. J. (1994), “Adjustment of Consumers' Durables Stocks: Evidence From Automobile Purchases," Journal of Political Economy, 102, 403-436.

Eichenbaum, M., and Hansen, P. L. (1990), "Estimating Models With Intertemporal Substitution Using Aggregate Time Series Data," Journal of Business \& Economic Statistics, 8, 53-69.

Elliott, G., Rothenberg, T. J., and Stock, J. H. (1996), "Efficient Tests for an Autoregressive Unit Root," Econometrica, 64 (4), 813-836.

Fleissig, R. A., Gallant, R. A., and Seater, J. J. (2000), "Separability, Aggregation, and Euler Equation Estimation," Macroeconomic Dynamics, 4, 547572

Grossman, J. S., and Laroque, G. (1990), "Asset Pricing and Optimal Portfolio Choice in the Presence of Illiquid Durable Consumption Goods," Econometrica, 58 (1), 25-51.

Hall, E. R. (1988), "Intertemporal Substitution in Consumption," Journal of Political Economy, 96, 339-357. 
Hall, P., and Horowitz, J. L. (1996), "Bootstrap Critical Values for Tests Based on Generalized-Method-of-Moments Estimators," Econometrica, 64 (4), 891-916.

Hanoch, G. (1977), "Risk Aversion and Consumer Preferences," Econometrica, 45 (2), 413-426.

Hansen, L. P. (1982), "Large Sample Properties of Generalized Method of Moments Estimators," Econometrica, 50 (4), 1029-1054.

Hansen, L. P., and Singleton, K. (1982), "Generalized Instrumental Variables Estimation of Nonlinear Rational Expectations Models," Econometrica, 50, 1269-1286.

(1983), "Stochastic Consumption, Risk Aversion, and the Temporal Behavior of Asset Returns," Journal of Political Economy, 91 (2), 249-265.

Hansen, P. L., Heaton, J., and Yaron, A. (1996), "Finites Sample Properties of Some Alternative GMM Estimators," Journal of Business \& Economic Statistics, 14, 262-280.

Johansen, S. (1991), "Estimation and Hypothesis Testing of Cointegration Vectors in Gaussian Vector Autoregressive Models," Econometrica, 59, 15511580 .

Kocherlakota, N. (1990), "On Tests of Representative Consumer Asset Pricing Models," Journal of Monetary Economics, 26, 285-304.

Lam, P. S. (1989), "Irreversibility and Consumer Durables Expenditures," Journal of Monetary Economics, 23, 135-150.

Lewbel, A. (1987), "Bliss Levels That Aren't," Journal of Political Economy, 95, 211-215.
Mankiw, N. G. (1982), "Hall's Consumption Hypothesis and Durable Goods," Journal of Monetary Economics, 10, 417-425.

(1985), "Consumer Durables and the Real Interest Rate," Review of Economics and Statistics, 67, 353-362.

$\mathrm{Ng}$, S., and Perron, P. (2001), "Lag Selection and the Construction of Unit Root Tests With Good Size and Power,' Econometrica, 69 (6), 1519-1554.

Ogaki, M. (1992), "Engel's Law and Cointegration,” Journal of Political Economy, 100, 1027-1046.

Ogaki, M., and Reinhart, C. M. (1998), "Measuring Intertemporal Substitution: The Role of Durable Goods,' Journal of Political Economy, 106 (5), 1078 1098.

Stigler, G., and Becker, G. (1977), "De Gustibus Non Est Disputandum,” American Economic Review, 67, 76-90.

Swensen, R. A. (2006), "Bootstrap Algorithms for Testing and Determining the Cointegration Rank in VAR Models," Econometrica, 74 (6), 1699-1714.

Tauchen, G. (1986), "Statistical Properties of Generalized Method of Moments Estimators of Structural Parameters Obtained From Financial Market Data," Journal of Business \& Economic Statistics, 4, 397-425.

West, K. D., and Wilcox, D. W. (1994), "Some Evidence on Finite Sample Distributions of an Instrumental Variables Estimator of the Linear Quadratic Inventory Model," in Inventory Cycles and Monetary Policy, ed. R. Fiorito, Berlin: Springer-Verlag, pp. 253-282.

Yogo, M. (2006), "A Consumption-Based Explanation of Expected Stock Returns," Journal of Finance, 61 (2), 539-580. 